OECD Trade and Environment Working Papers 2020/02

New Digital Technologies to Tackle Trade in Illegal Pesticides

\section{Clara Frezal,}

Grégoire Garsous 


\section{OECD TRADE AND ENVIRONMENT WORKING PAPERS}

This paper was approved by the Joint Working Party on Trade and Environment in July 2020 and prepared for publication by the OECD Secretariat.

This paper, as well as any data and any map included herein, are without prejudice to the status of or sovereignty over any territory, to the delimitation of international frontiers and boundaries and to the name of any territory, city or area.

The statistical data for Israel are supplied by and under the responsibility of the relevant Israeli authorities. The use of such data by the OECD is without prejudice to the status of the Golan Heights, East Jerusalem and Israeli settlements in the West Bank under the terms of international law.

Comments are welcome and can be sent to tad.contact@oecd.org. 


\title{
New Digital Technologies to Tackle Trade in Illegal Pesticides
}

\author{
Clara Frezal and Grégoire Garsous, OECD
}

\begin{abstract}
Global trade in illegal pesticides has been steadily growing in recent years, posing serious threats to agriculture, the environment, human health, and the economy. Evidence of this trend can be found in the increasing number of seizures of counterfeit, fake, and unauthorised pesticides, as well as their growing share in the global pesticide market. This paper identifies the main drivers and enablers of this illicit trade, and explores the potential of digital technologies, such as blockchain, to support policies to tackle this criminal activity. It also outlines the challenges in the adoption of these digital-based policy responses and discusses other available policy options.
\end{abstract}

Keywords: Blockchain, environment, supply chain, traceability

JEL Codes: Q55, Q16, Q17, Q18, F18

\section{Acknowledgements}

This paper has benefited from comments received by OECD colleagues Susan Stone, Rachel Bae, Silvia Sorescu, Javier Lopez Gonzalez (from TAD/EPI), Marie-Agnes Jouanjean and Francesca Casilini (from TAD/ARP), Sophia Gnych (TAD/COD), and Leon Van Der Wal (ENV/EHS). 


\section{Table of contents}

1. Introduction

2. Trade in illegal pesticides - a growing issue

3. Policy responses that can be supported by new digital technologies 18

4. Policy responses beyond new digital technologies 28

5. Conclusion

Tables

Table 1. Main types of blockchain segmented by permission model

\section{Figures}

Figure 1. The main steps of the pesticide registration procedure

Figure 2. Seizures of illegal pesticides as part of the Silver Axe operation

Figure 3. Global pesticide export value, 1990-2017

Figure 4. Top pesticides exporters in 1990 and 2017

Figure 5. Real world example of trade in illegal pesticides

Figure 6 . Information on the pesticide supply chain entered into the blockchain

\section{Boxes}

Box 1. Pesticide registration

Box 2. The Silver Axe Operation

Box 3. Blockchain: Key concepts and definitions

Box 4. The different types of blockchain technologies

Box 5. Border agency co-operation: Insights from the OECD Trade Facilitation Indicators (TFIs) 24

Box 6. The "one check principle", a successful example of inter-agency co-operation 


\section{Key messages}

- The growth of international trade in illegal pesticides poses a significant threat to agriculture, the environment, human health, and the economy. However, cracking down on these criminal activities has become more difficult due to the growing pesticide trade flows and increasing complexity of pesticide supply chains.

- Blockchain and other new digital technologies (e.g. big data, Al) hold significant promise to support the implementation of policy responses on traceability and authentication of pesticides, in addition to the monitoring and control of pesticide trade.

- The wider adoption of these digital tools by supply chain actors and control agencies could significantly reduce the risks of entry and sale of illegal pesticides.

- Their adoption is nevertheless challenging given the large upfront costs associated with IT development and infrastructures, and their complexity. This is especially the case for developing countries.

- While digital-based solutions may allow for the identification of criminal activities, they are insufficient to address the present issue. Policy actions other than those based on digital tools need to be implemented in parallel (e.g. raising public awareness, increasing sanctions). 


\section{Executive summary}

This paper explores the potential of blockchain technology - a digital distributed ledger system - to support the implementation of policy actions that can tackle the trade in illegal pesticides. Given that blockchain is usually used in parallel with other digital technologies - e.g. sensors for the creation of data, big data analytics, and artificial intelligence - the complementarity of these technologies is also discussed.

The growth of trade in illegal pesticides is a major concern. A large volume of counterfeit, fake and unauthorised pesticides are reaching farmers, with detrimental consequences for agriculture, the environment, human health, and the economy. Available estimates indicate that illegal pesticides account for a larger share of the pesticide market in developing countries, where regulatory and enforcement capacities are generally more limited. However, illegal pesticides are also present in developed countries, with most OECD countries having reported an increasing number of seizures of illegal pesticides in recent years. Importantly, trade in illegal pesticides must be addressed as a transnational issue, as most cases involve products crossing international borders before reaching their final destination.

The global growth in trade in illegal pesticides has been enabled by the globalisation of pesticide trade since the late 1990s, which has complicated the implementation of regulatory and trade control policies and created opportunities and incentives for fraud. Organised crime groups around the world are exploiting gaps in legislation and using the low effectiveness of traditional detection and control measures to trade poor quality and unregulated products, and extract high profit margins from their sale.

New digital technologies - the accessibility, capacity and application of which have boomed in recent years - offer opportunities to tackle this criminal activity. Blockchain, in particular, is considered a key technology to ensuring full traceability along complex global supply chains, and thereby reducing opportunities for fraud. In addition to the quick and accurate detection of illegal products, blockchain enables secure data exchange between multiple stakeholders and cross-organisation automation through the execution of smart contracts. Several blockchain applications for tracking products from source to store have been successfully piloted and are currently being implemented, including within the agro-food sector.

In addition to blockchain, other digital technologies such as big data analytics and artificial intelligence (AI) can help tackle trade in illegal pesticides by improving the effectiveness of trade control policies. These technologies offer opportunities for enhanced risk-management at borders, automated inspections of containers and cargos, and the monitoring of online trade. The wider adoption of these tools by Customs and other control agencies would significantly reduce the risk of entry and sale of illegal pesticides.

While holding great promise, the adoption of new digital technologies also presents challenges. The integration of blockchain tracking solutions, in particular, raises challenges linked to the high investment costs required for information technology (IT) development and infrastructure. This can hinder the adoption of digital solutions, especially in developing countries where financial resources are more constrained. Other challenges include the lack of quality control of the information entered into the system, and the limited interoperability between different blockchain platforms. Getting all the supply chain actors involved and aligned is also likely to be challenging, given the global nature and high number of participants in pesticide supply chains. This is nevertheless essential to ensure traceability and chain of custody of products at all stages of the supply chain.

Blockchain should not be considered a panacea for the trade in illegal pesticides. An effective strategy to tackle this criminal activity would require a combination of policy actions based on new digital technologies (e.g. blockchain, Al, big data analytics, the Internet of things) with other policy interventions, including raising public awareness of the risks that are associated with illegal pesticides and legislative solutions so as to mitigate their penetration on the global market. Such interventions would include, for example, strengthening sanctions and closing loopholes in legislation. 


\section{Introduction}

Over the past several years, new value chain and data management technologies - e.g. distributed ledger technologies such as blockchain - have been recognised for their potential to improve traceability in the increasingly integrated and complex agro-food supply chains. The proliferation of the resulting pilot projects could ultimately revolutionise the agro-food sector. Indeed, these new technologies seem to be particularly relevant in the context of complex value chains - often characterised by information asymmetry and misaligned incentives between stakeholders that create opportunities for fraud and illegal practices.

Pesticides are an important input of agricultural production. In recent years, however, trade in illegal pesticides has been expanding globally, posing serious threats to agriculture, the environment, and to the health of users and consumers of food (OECD, 2011 $\left.{ }_{[1]}\right)$. Cracking down on these criminal activities has become more difficult because of the increasing complexity of pesticide global supply chains. Pesticides can cross borders many times before reaching farmers - with the manufacturing, assembly and use of a product potentially taking place in different countries (Mace and Luda di Cortemiglia, 2016[2]). Together with the steady increase in cross-border pesticide trade, the complexity of supply chains has created greater opportunities for fraud. This complicates the traceability of products and challenges the effectiveness of traditional trade control policies.

This paper explores the opportunities offered by new digital technologies to curb trade in illegal pesticides. Two areas of policy action that could benefit from these technologies have been identified: i) the traceability and authentication system for pesticide products, and ii) the monitoring and control of pesticide trade, mostly at Customs border posts.

Blockchain technology has a strong potential to support the implementation of these two areas of policy action as it enables asset tracking and authentication, and reduces the transaction costs associated with co-ordination and information exchange among multiple stakeholders. In addition to blockchains, other digital technologies such as big data analytics and artificial intelligence (AI) could support strategies to tackle trade in illegal pesticides by improving risk management and fraud identification processes at the border. The wider adoption of these digital tools by supply chain actors and Customs and other control agencies could significantly reduce the risks of entry and sale of illegal pesticides.

This paper is organised as follows. Section 2 provides a definition of "illegal pesticides" and a discussion on their associated environmental and socio-economic risks. It then presents the specific challenges in the pesticide value chain, the main drivers and enablers of trade in illegal pesticides, and the methods used to smuggle these products. Section 3 explores policy responses to the trade in illegal pesticides and the potential contribution of new digital technologies -in particular blockchains - to facilitate their implementation. The challenges associated with the adoption and use of these technologies are also discussed. Section 4 briefly looks at other policy responses beyond new digital technologies that are essential to efficiently tackle this criminal activity. Concluding remarks are provided in the last section. 


\section{Trade in illegal pesticides - a growing issue}

Pesticides are an essential input of agricultural production. They are part of the package of agronomic inputs that has supported the large increase in the average yields and global production of major cereal crops since the 1960s (Popp, Petö and Nagy, 2015 $[3]$ ). ${ }^{1}$ The use of pesticides has also enabled higher farm profits by reducing the costs related to labour-intensive tasks such as hand weeding (Cunningham, n.d.[4]]).

Handled properly, the use of pesticides can result in growing more food on less land and, in some circumstances, help to contain the expansion and degradation of agricultural lands and the associated biodiversity loss and greenhouse gas (GHG) emissions from land-use change (Mahmood et al., 2016[5]). However, due to their toxic nature, pesticides can also represent a significant threat to the environment (National Pesticide Information Center, 2016 $\left.6_{[6]}\right)$. Pesticides applied over land can have detrimental effects on air, soil, and water quality, and on non-targetted plants and animals (Pesticide Action Network UK, $\left.2017_{[7]}\right)$. Furthermore, direct exposure to pesticides and the presence of pesticide residues in food can present risks for human health (Mahmood et al., 2016 $[5]$ ).

A strong regulatory framework often controls the use of pesticides in the agro-food chain to protect farmers, the environment and society as a whole. In most countries, pesticides are authorised for sale only after an independent, science-based risk assessment is conducted by a government agency to ensure that its correct use will not have adverse effects on the environment or on human health (ECPA, 2019 [8]; Ing. M.H. van Diesen, n.d.[9]). Whilst legitimate and necessary, these evaluations are costly and often limit the quantity of products available on the market, thereby increasing their price. This creates incentives for the manufacturing and trade of illegal pesticides to extract above market profits.

\section{Defining illegal pesticides}

A pesticide is a mixture of chemicals that contains one or more active ingredients and co-formulants used to prevent, destroy or control pests - including vectors of human or animal diseases, and unwanted species of plants or animals (OECD, 2018[10]; OECD, 2001 $[11]) .{ }^{2}$ Sub-categories of pesticides include insecticides, fungicides, herbicides, rodenticides, and plant growth regulators.

There is no official, internationally-shared definition of "illegal pesticides" (Mace and Luda di Cortemiglia, 2016[2]; Food Chain Evaluation Consortium, 2015[12]). The literature on this issue uses a variety of terms to describe illegal pesticides and provides different classifications of these products (Mace and Luda di Cortemiglia, 2016[2]). For the purpose of this study, the definition and categorisation in the OECD Best Practice Guidance (BPG) to Identify Illegal Trade of Pesticides will be used (OECD, 2018[10]).

\footnotetext{
${ }^{1}$ Since the 1960s, the growing application of fertiliser and pesticides, use of irrigation, and improved crop varieties also referred to as the "Green revolution" - led to drastic yield improvements in many parts of the world (OECD/FAO, 2019[73]).

2 The active ingredients provide the pesticide action, while co-formulants (e.g. emulsifiers, additives, water) facilitate the application of the product.
} 
According to this document, an illegal pesticide refers to any product that is not legal in the country where it is "placed on the market" (OECD, 2018 $[10])$. This includes:

- Counterfeit and fake pesticides: Illegal copies of a branded, legitimate pesticide. Counterfeit pesticides are characterised by high-quality fake branding and packaging, and may therefore be difficult to distinguish from a legal product. In contrast, fake pesticides can be more easily identified due to their poor quality and packaging (OECD, 2018[10]).

- Unauthorised pesticides: Pesticide products that are not authorised for use by the regulatory authorities in the country in which they are "being placed on the market" (OECD, 2018[10]). In most countries, pesticides must be registered by a national government agency, which ensures they meet the safety standards in force (Ing. M.H. van Diesen, n.d. $[9]$ ). Pesticide products that have not been registered are therefore considered illegal. Box 1 provides information on the procedure for pesticide authorisation and on data requirements for pesticide risk-assessment.

- Obsolete pesticides: Pesticide products that are no longer authorised or fit to purpose. Pesticides become obsolete for several reasons, including product deterioration or degradation, deterioration of the packaging and label, de-registration of the product - due to harmful health or environmental effects - or revised product use recommendations (OECD, 2018[10]; OECD, 2014[13]; Mace and Luda di Cortemiglia, 2016[?]).

\section{Box 1. Pesticide registration}

Pesticide registration is a scientific, legal, and administrative procedure which aims to ensure that a pesticide product is effective for its intended purpose and meets safety standards before it can be sold. Pesticide registration also involves the regular review of registered pesticides to ensure they meet the latest health and environmental risk-assessment standards. This re-evaluation process can lead to the removal of some products from the market (i.e. pesticide de-registration).

Companies that want to produce a new pesticide or active ingredient must submit a registration dossier to the competent government authority in the country of intended use. A pesticide product will be authorised for sale or export in a specific country only after a complete review and assessment of the submitted pesticide dossier and approval by the responsible authority (Figure 1).

Pesticide dossiers must usually include:

- Information on the product and its intended use

- Data to identify the product, i.e. identity, composition, and physical and chemical properties.

- Data to assess risks to humans and the environment, i.e. data on toxicity and on direct and indirect exposure, including residue assessment.

- Data to assess the efficacy of the product when used according to label instructions.

- Regulatory authorities often require a copy of the label to evaluate and approve the language and to ensure that instructions for use and safety measures are appropriate in the face of any potential risk.

Pesticide registration is a resource-intensive process. Studies required to support the registration of a pesticide can cost USD 10 million or more and take several years to complete. 


\section{Figure 1. The main steps of the pesticide registration procedure}

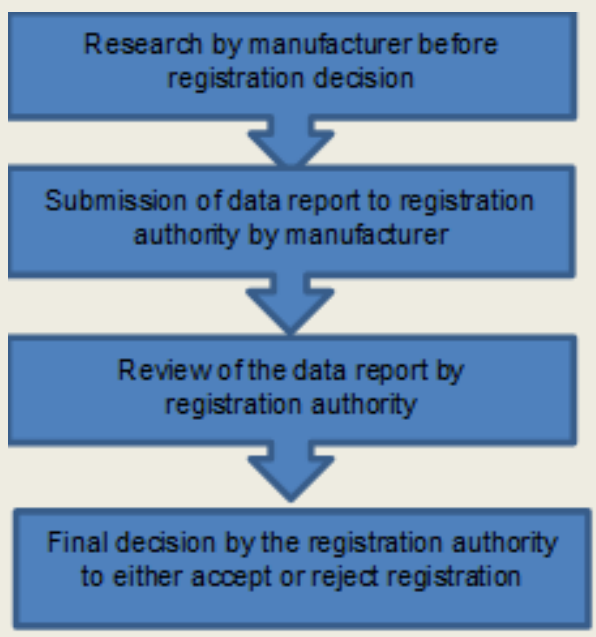

Source: (FAO/WHO, 2013[14]; US EPA, n.d.[15]; Ing. M.H. van Diesen, n.d.[9]; Mahmood et al., 2016[5]).

\section{Environmental and socio-economic impacts of illegal pesticides}

\section{Environmental risks associated with illegal pesticide use}

The impact of pesticide use on the environment is a major public concern. In addition to the poor targeting of such use, pesticides can spillover into the environment at different stages of its production, transportation, and storage (Pariona, 2017 $[16]) .{ }^{3}$ The environmental risks include (Kaur and Garg, 2014 [17]; Mahmood et al., 2016[5]; Aktar, Sengupta and Chowdhury, 2009 [18]):

- Surface and ground water contamination from leaching, runoff or spray drift, and related negative impacts on aquatic forms of life (i.e. aquatic plants and fishes).

- Soil contamination and adverse effects on soil fertility due to the decline of beneficial soil microorganisms and insects (e.g. soil bacteria, fungi, earthworms).

- Air contamination from spray drift or volatilization.

- Adverse effects on non-targetted organisms. Pesticide use has been associated with the decline of some insects (e.g. pollinators and predators), and on bird and mammal populations, including endangered species. The application of pesticides can also affect non-targetted plants and crops, and injure nearby trees and shrubs.

The probability of the occurrence and magnitude of these environmental risks depends primarily on: a) the chemical properties of the pesticides, which determine pesticide transport, persistence, and water solubility; and b) the application method, timing, and pest management techniques and processes used by the farmer (Pesticide Action Network, 2010[19]).

\footnotetext{
${ }^{3}$ Research has shown that over $98 \%$ of sprayed insecticides and $95 \%$ of herbicides reach a destination other than their target pest (Pariona, 2017 $[16])$.
} 
In view of these environmental risks, most countries require an environmental-risk assessment of pesticide products before they can be sold and used (Box 1). Government agencies use exposure information and eco-toxicity data to evaluate the potential adverse effects on non-target organisms, air, soil, and water. They then consider whether the safety measures proposed by the manufacturer are appropriate to prevent environmental hazards (WTO and FAO, 2013[20]).

Precisely because illegal pesticides do not go through, or have not been cleared by, this procedure, they represent a significantly higher threat to the environment than legitimate, regulated pesticides. The chemical composition of illegal pesticides is unknown as they have been neither tested nor approved by a governmental agency and their labels often misrepresent the product's content. There is therefore no precise knowledge about their impact on the crops and ecosystems in which they are used (Streloke, 2018[21]).

Illegal pesticides can be inefficient at protecting crops from pests, leading to the spread of diseases on cultivated lands, to higher dosage requirements, and/or a more frequent application of these products compared to legitimate pesticides. (Malkov, Prischepa and Kutonova, 2015[22]; Federation of Indian Chambers of Commerce and Industry, 2015[23]). Moreover, illegal pesticides can destroy and spoil crops, or provoke soil infertility, with farmers no longer able to cultivate the contaminated land, as even the smallest change in pesticide composition can disproportionately increase toxicity (Malkov, Prischepa and Kutonova, 2015[22]; UN environment, 2018[24]). Several cases of major damage to crops after the use of an illegal pesticide have been documented. In 2005, for instance, five farms in the Russian Federation (hereafter "Russia") and Ukraine reported sugar beet crops losses of up to 75 hectares. The farmers had used a fake pesticide product which they believed to be a legitimate herbicide (ECPA, 2008[25]).

Incorrect pesticide formulations are also likely to have a significantly longer half-life period, translating into long-term contamination of soil, and ground and surface water which threaten terrestrial and aquatic biodiversity (Malkov, Prischepa and Kutonova, 2015[22]). ${ }^{4}$ Obsolete pesticides are characterised by higher toxicity and environmental persistence, and lower water solubility, and can accumulate in the fatty tissue of living organisms (Pesticide Action Network, 2010[19]).

Finally, the absence or inaccuracy of usage direction on the labels of illegal pesticides can lead to its inappropriate application in terms of the methods, quantities, and precautions to be undertaken. For legitimate products, there is an obligation to include an "Environmental Hazard" section on labels, which gives directions to minimise risks to the environment. Labels should also include instructions regarding the proper storage and disposal of unused pesticides (National Pesticide Information Center, 2016 $\left.6_{[6]}\right)$. The lack of such information can exacerbate the environmental risks associated with illegal pesticides use.

\section{Health, economic and social impacts of illegal pesticides}

Direct (i.e. pesticide inhalation, ingestion or skin penetration) and indirect (i.e. intake of food produced using pesticides) exposure to pesticides can present risks for human health. ${ }^{5}$ Human health riskassessment of pesticides is therefore required before they can be sold and used (Box 2). The presence of pesticide residues in food is tightly regulated in some markets, with maximum residue level (MRL)

\footnotetext{
${ }^{4} \mathrm{~A}$ half-life is the time it takes for a certain amount of a pesticide to be reduced by half. This occurs as it dissipates or breaks down in the environment (National Pesticide Information Center, n.d.[70]).

${ }^{5}$ Exposure to pesticides can be associated with both acute and chronic health effects. Acute effects are immediate effects, including headache, skin itching, irritation of the nose and throat, diarrhoea, vomiting, blurred vision, blindness, and (very rarely) death. Chronic effects are long-term effects, including neurological health effects, damage to the immune system and multiple body organs, and blood diseases. Exposure to pesticides for prolonged periods of time can also affect reproductive capabilities and has been associated with cancers (Mahmood et al., 2016[5]).
} 
standards ensuring that food produced using pesticides is safe for human health and thus suitable for consumption (ECPA, 2019[8]).

As with environmental risks, the use of illegal pesticides poses additional health threats to users - mainly farmers - and consumers of food because these products have neither been tested nor approved by a government agency for their impact on human health, and may contain highly toxic substances. In addition, their labels often contain incorrect and inadequate safety and personal protection protocols. The fact that the content of illegal pesticides is unknown also increases the time needed to identify the right treatment in case of intoxication (Malkov, Prischepa and Kutonova, 2015[22]).

Moreover, the use of illegal pesticides is associated with adverse economic implications. First, illegal pesticide use can lead to loss of revenues for farmers due to decreases in crop yields or more severe damage to crops (OECD, 2011 $[1])$. In low-income countries, this can worsen poverty and threaten food security. Farmers using illegal pesticides can also face rejection of their products by food companies or customs authorities (when these products are for export) due to excessive residue levels (Mace and Luda di Cortemiglia, 2016[2]). Farmers might then suffer reputational damage, and subsequent losses in business, which in some cases can affect whole countries where such agricultural and food commodities have been produced, resulting in a total or partial export ban (Malkov, Prischepa and Kutonova, 2015[22]).

The use of illegal pesticides also generates costs for legitimate companies, affecting their reputation and creating trade distortions and unfair competition (OECD, 2011 ${ }_{[1]}$ ). Legitimate pesticide producers face losses in sales as lower priced copies of their products reach the market, adversely affecting employment in the pesticide industry as well as decreasing demand for inputs from upstream sectors (Wajsman, Arias Burgos and Davies, 2017[26]). Legitimate businesses also suffer reputational consequences, including a decrease of consumer confidence because of trademark infringement by counterfeiters (Fishel, 2015[27]). Trade in illegal pesticides could also reduce innovation by discouraging legitimate producers from investing in research and development (R\&D) to develop new, high quality products (Mace and Luda di Cortemiglia, 2016[2]).

Reduced activity in the legitimate pesticide industry also has an impact on government revenue. As for any illegal activity, actors engaged in the manufacture and trade of illegal pesticides do not declare their revenue to authorities and therefore do not pay taxes on the latter (Wajsman, Arias Burgos and Davies, $2017_{[26]}$ ). These losses in government tax revenue further reduce regulatory capacity and enforcement resources (Mace and Luda di Cortemiglia, 2016[2]).

The European Union Intellectual Property Office (EUIPO) estimates that when both direct and indirect effects are taken into account, counterfeiting in the pesticide sector causes approximately EUR 2.8 billion of lost sales to the EU economy, which in turns leads to employment losses of about 11700 jobs and a loss of EUR 238 million in government revenue (Wajsman, Arias Burgos and Davies, 2017[26]]).

Trade in illegal pesticides can also have detrimental effects on the functioning of societies and public authorities as it is often associated with corruption and sometimes with other areas of crime (OECD, $\left.2011_{[1]}\right)$. Organised crime groups (OCGs) and networks engaged in the production and distribution of illegal pesticides often rely on corrupt custom officers, law enforcement officials, and staff in charge of pesticide procurement (Mace and Luda di Cortemiglia, 2016 $\left.{ }_{[2]}\right)$. Attractive profit margins contribute to conspiracy and corruption at every stage of the pesticide life cycle, complicating the control and prosecution of criminal activity (Malkov, Prischepa and Kutonova, 2015[22]). Finally, trade in illegal pesticides undermines national registration and risk reduction schemes, weakening public confidence in regulatory and compliance policies put in place by governments (OECD, 2011 $\left.{ }_{[1]}\right)$. 


\section{Estimating the size of trade in illegal pesticides}

Trade in illegal pesticides refers to any form of trade in a pesticide that violates the law of importing countries, including counterfeit, fake and un-registered pesticides (see definition, pp. 7-8) (OECD, $2019_{[28]}$ ). It is difficult to find detailed data on the magnitude (i.e. trade volume and value) and growth of trade in illegal pesticides because of its unlawful nature (ECPA, 2008[25]). Available estimates are based on scattered data (e.g. collected during control and investigation) and vary widely, as is the case for all sectors affected by counterfeiting and illegal activities (ECPA, 2008 ${ }_{[25]}$; OECD, $2011_{[1]}$ ).

Another challenge arises from the fact that the discovery of illegal pesticides is not always declared, as authorities may prefer to deal discreetly and directly with the concerned parties. One explanation for this approach is the desire to avoid reputational consequences and legal repercussions associated with the distribution and use of such pesticides.

By one estimate, the share of illegal pesticides on global markets increased from 5\%-7\% to $10 \%$ between 2007 and 2011 (Guyer and Davreux, 2012[29]). Since then, estimates have ranged from 10\% to 15\%, and up to $25 \%$ according to the Organization for Security and Co-operation in Europe (OSCE) (Europol, 2011[30]; Malkov, Prischepa and Kutonova, 2015[22]; Food Chain Evaluation Consortium, 2015[12]; UN environment, 2018[24]).

With the global pesticide market valued at over USD 60 billion, global revenues associated with the trade of illegal pesticides are estimated at USD $6-10$ billion, which is comparable to the annual global market of illegal transportation of waste (USD 10-12 billion) and endangered species (USD 7-23 billion). This makes trade in illegal pesticides one of the top ten most lucrative organised crime businesses in the world (Malkov, Prischepa and Kutonova, 2015[22]; Mace and Luda di Cortemiglia, 2016[2]).

The scope and scale of illegal pesticide presence varies from one market to another depending on regional and individual country specificities (ECPA, 2008 $\left.{ }_{[25]}\right)$. National farmers and industry associations in Africa estimate that $15 \%$ to $20 \%$ of the pesticide market is illegal, with particular hotspots where small scale domestic preparations and imports of illegal agricultural chemicals and counterfeit pesticides may account for up to $80 \%$ of the pesticide market (Guyer and Davreux, 2012[29]). In Asia, notably in the People's Republic of China (hereafter "China") and India, illegal pesticides are a major issue. In these two countries, illegal pesticides are estimated to account for approximately $30 \%$ of the pesticide market; in India, $30 \%$ of this market is estimated to be the result of illegal imports (Mace and Luda di Cortemiglia, 2016 ${ }_{[2]}$; Federation of Indian Chambers of Commerce and Industry, 2015[23] ${ }^{6}{ }^{6}$ In Brazil - the leading agricultural exporter in South America - illegal trade in pesticides is considered to account for a significant and growing share of the national pesticide trade, which was estimated at around 9\% in 2009 (OECD, 2011 [1]). Illegal pesticides are also a major concern in Argentina, Paraguay, and Uruguay (Mace and Luda di Cortemiglia, 2016[2]).

Farmers in developing countries are particularly vulnerable to illegal pesticides due to relatively more limited regulatory and enforcement capacities, and limited public awareness of this issue (Mace and Luda di Cortemiglia, 2016[2]). The scale and growth of illegal pesticides in developing countries is particularly worrying as significant agricultural productivity increases are needed to support food security and farmer livelihoods (Federation of Indian Chambers of Commerce and Industry, 2015[23]).

\footnotetext{
${ }^{6}$ In these two countries, the increase in the illegal pesticide market has been facilitated by the rapid growth of chemicalmanufacturing capabilities - including agricultural chemicals - over the last decade (RSK ADAS Ltd, 2015[38]). This suggests that illegal actors are able to source and produce illegal pesticides in countries that produce and distribute the legitimate chemical precursors (Food Chain Evaluation Consortium, 2015[12]).
} 
While illegal pesticides seem to be a bigger issue in developing countries, it is also a large and growing concern in developed countries, in particular European countries which have large agricultural sectors. Illegal pesticides have been estimated at over 10\% of the EU pesticide market (Mace and Luda di Cortemiglia, 2016[2]; Food Chain Evaluation Consortium, 2015[12]). More recently, EUIPO estimated that counterfeit pesticides accounted for $13.8 \%$ of pesticide sales in the European Union, resulting in the loss of about EUR 1.3 billion in sales for the legitimate pesticide industry (Wajsman, Arias Burgos and Davies, 2017[26]).

The main source of illegal pesticides in Europe is illegal parallel imports, where legitimate parallel imports of products are substituted with illegal copies. ${ }^{7}$ Illegal parallel traders import non-original chemicals from third countries, then place them in new containers and sell them to farmers as if they were originals that have been purchased in another EU country to permit legitimate price competition. This is possible due to the lack of requirements to link parallel imported products to their batch of origin, i.e. their reference batch number, at the time of sale (Section 4) (Food Chain Evaluation Consortium, 2015[12]; European Crop Protection Association, $\left.2019_{[31]}\right) .^{8}$

In view of the proliferation of illegal pesticides in Europe, in 2015 Europol started the Silver Axe Operation, an annual enforcement operation that targets trade in illegal pesticides. Data on seizures from this operation give further indication of the magnitude and growth of this criminal activity within Europe (Box 2).

\section{Box 2. The Silver Axe Operation}

The Silver Axe operation is an annual enforcement operation that originally focused on the sale and import of illegal pesticides in Europe, but which currently operates beyond European borders. It is coordinated by Europol, with support from the European Anti-Fraud Office (OLAF). At its launch in 2015, the Silver Axe operation involved seven EU countries. The number of participating countries has increased since to thirty-two in 2020, including six non-EU members.

This international operation involves close collaboration between law enforcement agencies to exchange and analyse data, and liaison between European and international plant protection bodies (e.g. CropLife, European Crop Protection Agency), and private pesticide companies.

In the course of the five editions of the Silver Axe operation, police and law enforcement officers have carried out checks at major seaports, airports, and land borders, as well as at pesticide production and repackaging facilities in participating countries. These have resulted in the seizure of 2568 tonnes of illegal pesticides across Europe (Figure 2). In 2020, seizure of illegal pesticides reached a record high of 1346 tonnes, roughly enough to spray $75 \%$ of farmland in France (i.e. $207000 \mathrm{~km}^{2}$ ). The fifth edition of the Silver Axe operation also led to the arrest of two individuals.

\footnotetext{
${ }^{7}$ Parallel imports can be defined as the ability to import a product under IPR protection, without the consent from the IPR holder, from another market where it is also produced but at a lower price. This process generally involves some repackaging in order to meet markets access requirements (e.g. translation of the safety instructions). In the European Union, parallel imports of pesticide products is legal. However, it has been increasingly misused to move illegal pesticides around the European Union and bring them to the market.
}

${ }^{8}$ According to European industry body, source countries for imported illegal pesticides include China, India, Malaysia, Indonesia, Turkey, and Ukraine (Food Chain Evaluation Consortium, 2015[12]). 


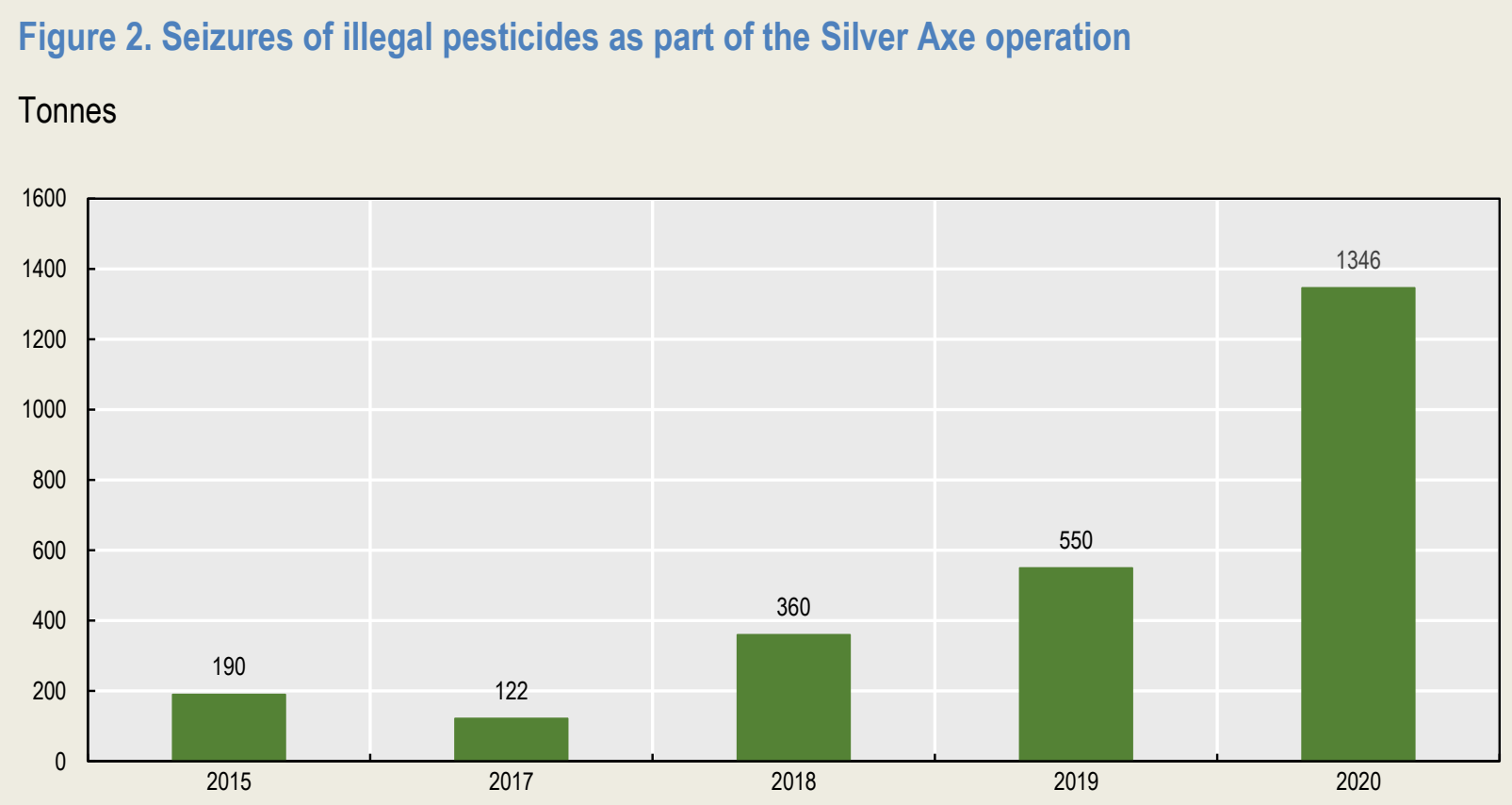

Source: (Europol, 2017[32]; Europol, 2015[33]; Europol, 2019[34]; Europol, 2018[35]) (Europol, 2020[36]).

\section{Key drivers and enablers of trade in illegal pesticides}

Several factors have contributed to an increase in trade in pesticide products. The global growth in demand for agricultural production - due to rising world population and increasing per capita wealth - has led to an increase in demand for pesticides. As a result, cross-border trade in legal pesticides has increased dramatically, especially over the last decade (Figure 3). These growing trade flows have put strong pressure on border authorities who often lack the resources to ensure proper oversight, leading to a corresponding rise in illegal pesticide trade (Mace and Luda di Cortemiglia, 2016 ${ }_{[2]}$ ). While not all illegal pesticides are the result of trade (as noted above, some are the result of "home grown" providers), this paper focuses on the role of such trade in the proliferation of illegal pesticides.

Illegal pesticides are attractive to farmers because they are less expensive than legitimate products. Their price can be as much as $40 \%$ lower than the price of legitimate, branded pesticides (Federation of Indian Chambers of Commerce and Industry, 2015[23]). Demand for illegal pesticides can also be explained by end users' lack of awareness of the risks associated with their use and on how to identify them (Federation of Indian Chambers of Commerce and Industry, 2015[23]; UN environment, 2018[24]; Mace and Luda di Cortemiglia, 2016[2]). It can be extremely difficult for farmers to differentiate between authentic and illegal pesticides as counterfeiters use elaborate techniques to make their products appear genuine (see next section). Finally, demand exists for unauthorised pesticides, including broad-spectrum pesticides that are banned in many markets across the world (Ing. M.H. van Diesen, n.d.[9]).

In addition, the shape of pesticide supply-chains is changing and global supply chains are becoming increasingly complex, involving up to twenty-five different entities - ranging from manufacturers to shippers and distributors - with production, shipment, assembly, and distribution points scattered over multiple 
geographical locations. The number of parties, transfers, and stops involved in the pesticide trade has complicated regulatory and control efforts, as well as the identification of illegal products (Mace and Luda di Cortemiglia, 2016[2]).

\section{Figure 3. Global pesticide export value, 1990-2017}

USD billion

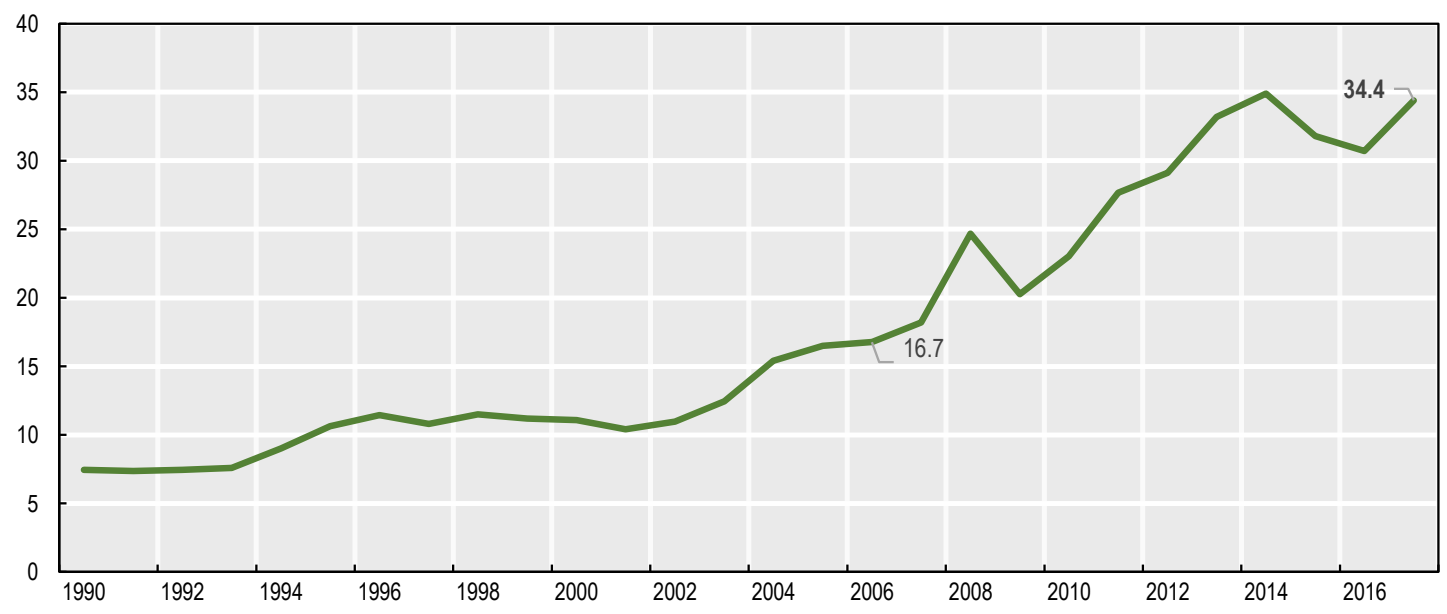

Source: (FAOSTAT, 2019[37]).

Until the 1990s, pesticide manufacturing was concentrated in a few countries, with Germany, the United States, France, and the United Kingdom accounting for the majority of global pesticide exports. Since then, several new legitimate pesticide exporters - including China and India - have emerged leading to a diversification of suppliers on the global marketplace (Figure 4).

Inspection and tracking systems have not kept up with this growing complexity. As a result, a large share of illegal pesticides has been moving through legitimate supply chains without detection or seizure. This low risk of detection - together with the minor legal or financial consequences associated with the seizure of illegal pesticides in most jurisdictions - have increased opportunities and incentives for fraud, enabling this criminal activity to expand globally.

Another key driver of trade in illegal pesticides is the high profit margin associated with this criminal activity. According to the Federation of Indian Chambers of Commerce and Industry (FICCl), the margins on nongenuine illegal pesticides can be as high as $25-30 \%$, compared to $3-5 \%$ for legitimate products (Federation of Indian Chambers of Commerce and Industry, 2015[23]). Several factors contribute to these high profit margins. First, through the production of illegal pesticides, criminal actors avoid all costs associated with the development and marketing of a new brand name product (e.g. R\&D costs) (Mace and Luda di Cortemiglia, 2016[2]), nor do illegal producers face the high regulation costs associated with pesticide authorisation (Box 1). Indeed, pesticide registration is a long and costly process that can act as a barrier to entry for new businesses, making illegal activities attractive for criminal actors (Federation of Indian Chambers of Commerce and Industry, 2015[23]]).

In addition, illegal producers might incur considerably lower production costs due to the poor composition of their products. Illegal pesticides are usually less concentrated than legitimate products, contain cheaper or smaller quantities of active ingredients, and can be made of diluted and obsolete pesticide stocks or even from water or talc (RSK ADAS Ltd, 2015[38]; ECPA, 2008[25]). 
Figure 4. Top pesticides exporters in 1990 and 2017

Share of global pesticide export value

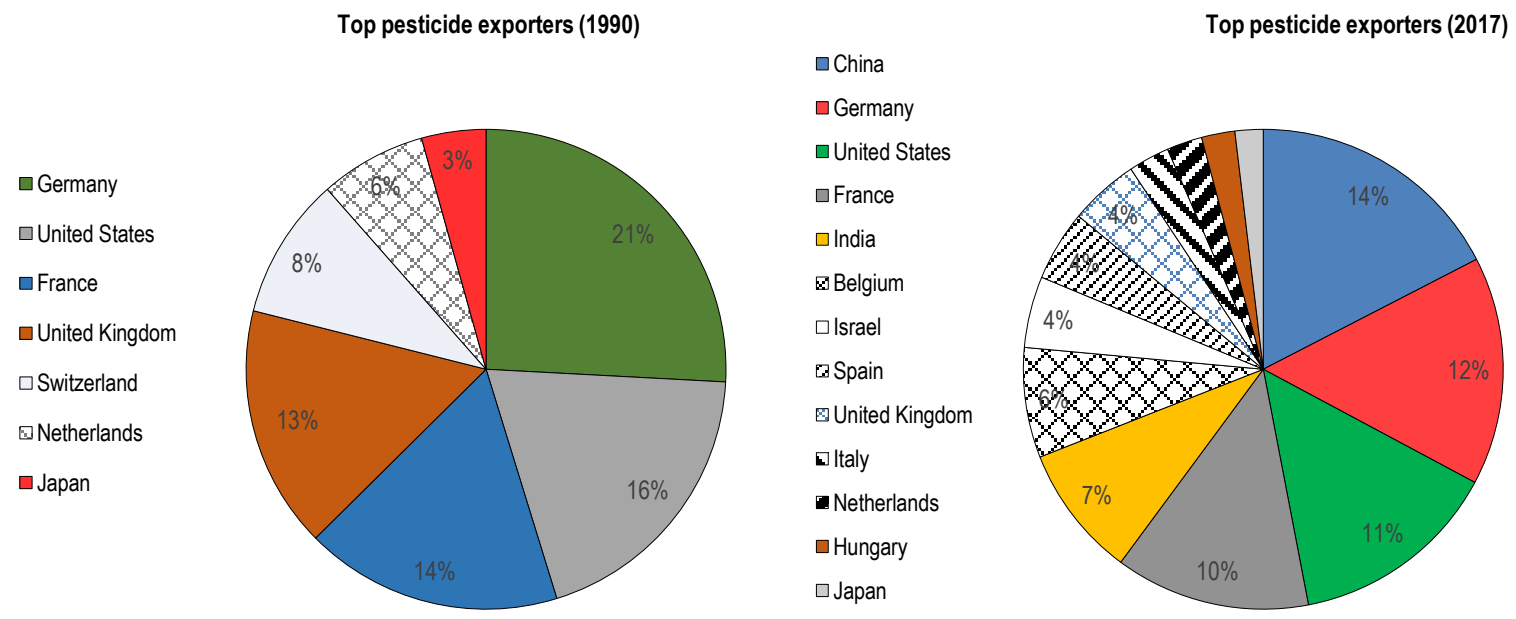

Note: Taken together, these countries accounted for $80 \%$ of total pesticides export value in 1900 and 2017 , respectively Source: (FAOSTAT, 2019[37]).

\section{Methods used to smuggle illegal pesticides}

Actors engaged in trade in illegal pesticides range from loosely organised groups - sometimes just a few individuals - to highly organised criminal networks. There is growing evidence that sophisticated counterfeits are produced and distributed by large organised criminal groups (OCGs), which undertake the majority of illegal trans-border shipments (Mace and Luda di Cortemiglia, 2016[2]; ECPA, 2008[25]).

Misrepresentation of product content is one of the main methods used by illegal actors to avoid risk-profiling measures at custom borders, as well as regulatory and customer scrutiny. Illegal actors relabel and repackage pesticides, or refill legitimate pesticide containers to make their products appear genuine (Europol/OHIM, 2015 ${ }_{[39]}$ ). Forged transport documents are also used to conceal the content of containers and packages (Europol/OHIM, 2012[40]). As importing unbranded items is not illegal, criminal actors might further avoid border detection by sending products and labels separately - possibly through different ports - and printing counterfeit trademark labels on their products just before sale (Europol/OHIM, 2015[39]; Mace and Luda di Cortemiglia, 2016 $\left.6_{[2]}\right)$. Criminal networks also import active ingredients to be formulated, packed, and labelled near or within the country of destination, which prevents detection at the border and complicates the traceability of finished products (Mace and Luda di Cortemiglia, 2016[2]; Food Chain Evaluation Consortium, 2015[12]; OECD, 2011 $\left.1_{[1]}\right) .^{9}$

Criminal groups also rely on various sophisticated techniques to disguise the origin and provenance of illegal pesticides, and hinder product traceability along the supply chain (Mace and Luda di Cortemiglia, $\left.2016_{[2]}\right)$. This includes the use of deliberately complex and long transit routes, crossing borders of multiple countries, and relying on several modes of transportation (e.g. sea, air, overland transport) (Ing. M.H. van Diesen, n.d.[9]; Europol/OHIM, 2012[40]]). Forged transport documents are used to conceal the point of origin. Moreover, criminal actors can avoid detection by using distribution warehouses and self-storage

\footnotetext{
${ }^{9}$ It is also more lucrative to only transport active ingredients and to add other product constituents near the point of sale as active ingredients might only make up for about $1-5 \%$ of the total product.
} 
facilities in transit countries for the assembly and distribution of illegal pesticides. They can also fail to declare a product for customs control at checkpoints or reroute a shipment (Mace and Luda di Cortemiglia, 2016[2]]. Figure 5 illustrates the complexity and transnational character of trade in illegal pesticides.

Finally, illegal actors can sell their products directly to farmers via the Internet, which has become a major enabler for the distribution and sale of counterfeit and illegal pesticides (Mace and Luda di Cortemiglia, $\left.2016_{[2]}\right)$. For instance, illegal pesticides imported in the United States as a result of online sales on Amazon are estimated to be large in number, with nearly 4000 violations of the Federal Insecticide, Fungicide, and Rodenticide Act (FIFRA) recorded over the last five years (Clarridge and V.Mapes, 2018[41]). ${ }^{10,11}$ Moreover, online sales of pesticides usually involve small parcels that do not always follow the same path as large shipments and often cross borders via postal or express services, reducing the effectiveness of traditional detection and seizure strategies (Jouanjean, 2019 ${ }_{[42]}$ ) (Malkov, Prischepa and Kutonova, 2015[22]). ${ }^{12}$

\section{Figure 5. Real world example of trade in illegal pesticides}

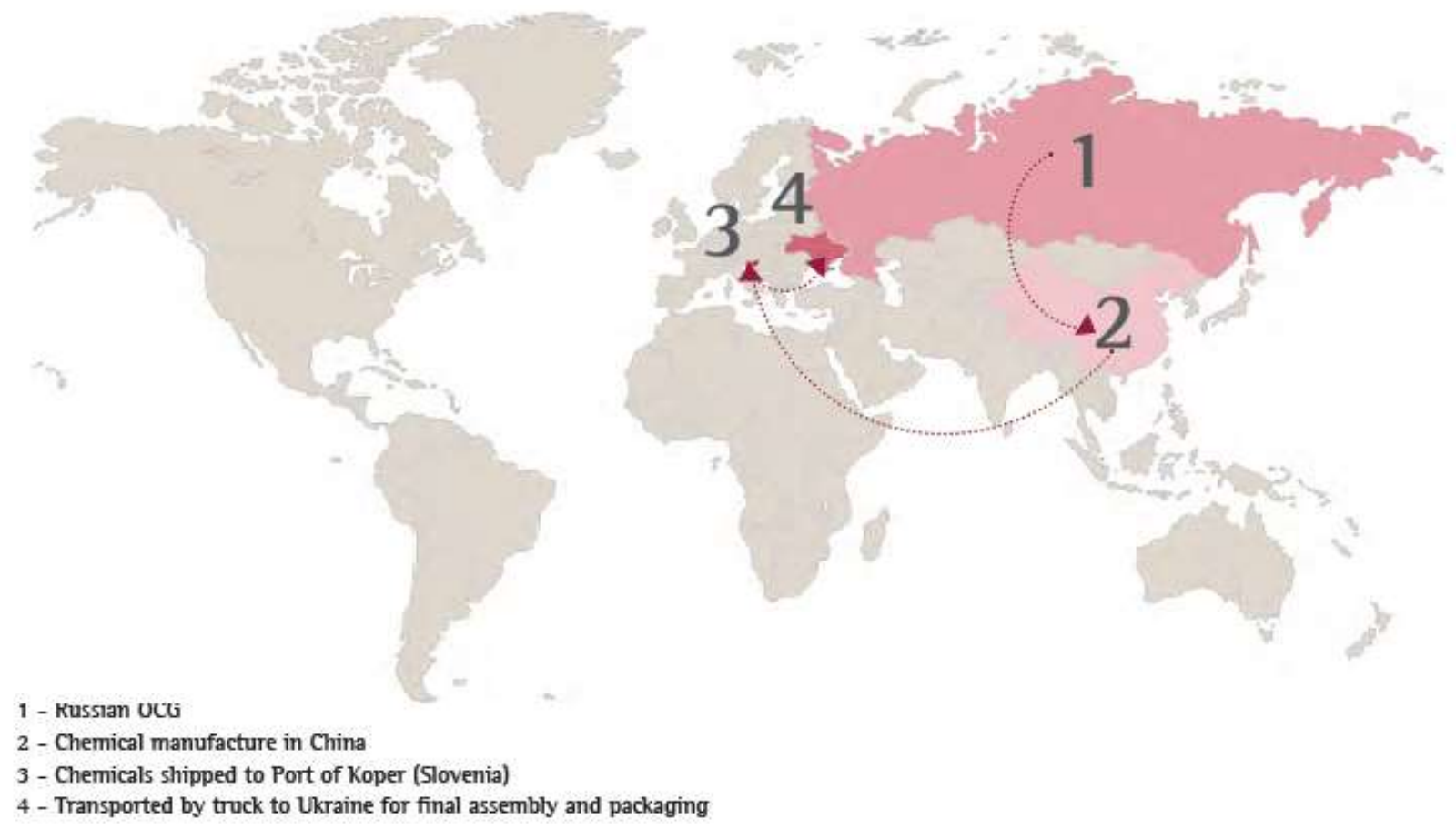

Note: A Russian OCG which acts as a broker, orders chemicals used in the production of pesticides from China. The chemicals are transported by container shipments to a port in Slovenia and then by truck into Ukraine, where the pesticides are manufactured, labelled, and packaged for further distribution across the European Union.

Source: (Europol/OHIM, 2015[39]).

${ }^{10}$ FIFRA is the federal statute that governs the registration, distribution, sale, and use of pesticides in the United States.

${ }^{11}$ Amazon has been ordered by the US Environmental Protection Agency to pay fines of USD 1.2 million for allowing third parties to sell imported unregistered pesticides in the United States (Clarridge and V.Mapes, 2018[41]).

12 According to the OSCE, $70 \%$ of counterfeit pesticides are sent in small packages to private agricultural producers and small farmers (Malkov, Prischepa and Kutonova, 2015[22]). 
Thus, trade in illegal pesticides has been underpinned by an increasingly sophisticated fraud system that traditional traceability and risk management systems have struggled to control. Consequently, government agencies have to reconsider their fraud detection and enforcement tools, and develop a range of policy responses to these new challenges, the implementation of which could benefit from the use of digital technologies such as blockchain.

\section{Policy responses that can be supported by new digital technologies}

Based on the discussion in Section 2, two areas of policy action that could benefit from the support of new digital technologies have been identified: i) the traceability and authentication system for pesticide products; and ii) the monitoring and control of pesticide trade, mainly at custom borders.

This section provides definitions of the new digital technologies that could be used to counter trade in illegal pesticides. It then explores their potential to facilitate the implementation of specific policy responses, with a focus on enhancing the security and integrity of pesticide authentication and traceability system, and improving the effectiveness of trade control policies for pesticide products. Risks and challenges associated with the adoption and use of these technologies are also discussed.

\section{New digital technologies: Definitions and concepts}

Blockchain technology is a form of distributed ledger technology (DLT) that acts as an open and trusted record of transactions from one party to another (or multiple parties) and that is not stored by a central authority (Box 3) (Berryhill, Bourgery and Hanson, 2018[43]). The core characteristics of blockchain are the following (Gaspar, 2019[44]):

- A decentralised system that is not reliant on trust: No single individual or entity is trusted with record keeping. Instead, all actors within the blockchain can validate the change of state of the ledger. This eliminates the possibility of fraud by one single authority.

- Data provenance: The time and origin of every entry into the blockchain is easily identifiable and traceable.

- Immutability: It is (almost) impossible to change or delete records once these have been entered into the blockchain.

\section{Box 3. Blockchain: Key concepts and definitions}

Distributed Ledger Technology (DLT): A technology upon which records of transactions are spread across multiple sites, countries or institutions, and is typically public. Transaction records are stored one after the other in a continuous ledger; entries can only be added when participants confirm the feasibility and validity of the transaction.

Node: A node is a user or computer on a blockchain platform that stores the ledger.

Cryptography: The act of creating codes that allows data to be kept secret. Cryptography converts this data into a format that can only be read/decoded by authorised users. Thus, the data can be transmitted without fear of it being decrypted and compromised by unauthorised actors. Authorised actors may 
decrypt the data using a "key", which is essentially a corresponding private code that only an authorised user should know.

Tokenisation: This term describes the process of transferring rights to a real world asset into a digital representation - or token - on the blockchain. Being in possession of that digital token gives one the right to that asset and the ability to trade and track it digitally. There are three main types of tokens:

- Payment token: Commonly known as a cryptocurrency, a payment token can be a store of value and a unit of measurement, e.g. Bitcoin.

- Utility token: Represents the right to a good or service similar to a gift card, e.g. StorjCoin.

- Security token: Provides equity or equity-like investment in a company. The holder of such a token has rights to a company's future profits, e.g. tZERO.

Source: (Berryhill, Bourgery and Hanson, 2018[43]; OECD, n.d.[45]).

There are many different blockchain technologies, all presenting different features and modes of governance. The most appropriate type of blockchain will depend on the problem it is intended to solve (Box 4).

Big data analytics allows for the processing and interpretation of large volumes of structured and unstructured data in different formats to infer relationships, establish dependencies, and perform predictions of outcomes and behaviours. Such analysis can help inform real-time decision-making by combining a wide range of information from different sources (Jouanjean, 2019[42]) (Okazaki, 2017[46]).

Artificial intelligence $(\mathrm{Al})$ is defined as the ability of machines and systems to acquire and apply knowledge and to carry out intelligent behaviour. Al or cognitive-based technologies help computers interact, reason, and learn like human beings to perform a broad variety of cognitive tasks that normally require human intelligence. This includes visual perception, speech recognition, decision-making, and translation between languages. Intelligent systems usually rely on a combination of big data analytics, cloud computing, machine-to-machine communication and connected devices - internet of things (IoT) - to learn and operate (Jouanjean, 2019[42]).

\section{Box 4. The different types of blockchain technologies}

Two of the most important features of blockchain technology are the "openness" of the platform (i.e. public or private) and the level of permissions required to add information to the blockchain (i.e. permissioned or permission less) (Table 1). In the context of public permission less blockchain, such as Bitcoin, anyone can read and add data to the ledger.

For supply chain traceability and management, a public-permissioned blockchain seems to be the most appropriate. Public-permissioned ledgers can greatly enhance accountability as transactions can be made transparent to everyone (e.g. consumers), while only authorised users are able to actually record new transactions (Berryhill, Bourgery and Hanson, 2018[43]). For our use case, regulatory authorities or a blockchain provider could be in charge of issuing permission to write on the ledger to legitimate actors along the pesticide supply chain. These actors will be responsible for updating the blockchain and maintaining a decentralised system. 
Table 1. Main types of blockchain segmented by permission model

\begin{tabular}{|c|c|c|c|c|c|c|}
\hline \multirow{5}{*}{$\begin{array}{l}\text { Blockchain } \\
\text { types }\end{array}$} & & & Read & Write & Commit & Example \\
\hline & \multirow[t]{2}{*}{ Open } & $\begin{array}{l}\text { Public } \\
\text { permission less }\end{array}$ & Open to anyone & Anyone & Anyone & $\begin{array}{l}\text { Bitcoin, } \\
\text { Ethereum }\end{array}$ \\
\hline & & $\begin{array}{l}\text { Public } \\
\text { permissioned }\end{array}$ & Open to anyone & $\begin{array}{l}\text { Authorised } \\
\text { participants }\end{array}$ & $\begin{array}{l}\text { All subset of } \\
\text { authorised } \\
\text { participants }\end{array}$ & $\begin{array}{l}\text { Supply chain } \\
\text { ledger for retail } \\
\text { brands viewable } \\
\text { by public }\end{array}$ \\
\hline & \multirow[t]{2}{*}{ Closed } & Consortium & $\begin{array}{l}\text { Restricted to an } \\
\text { authorised set of } \\
\text { participants }\end{array}$ & $\begin{array}{l}\text { Authorised } \\
\text { participants }\end{array}$ & $\begin{array}{l}\text { All or subset of } \\
\text { authorised } \\
\text { participants }\end{array}$ & $\begin{array}{l}\text { Multiple banks } \\
\text { operating shared } \\
\text { ledger }\end{array}$ \\
\hline & & $\begin{array}{l}\text { Private } \\
\text { permissioned } \\
\text { ("enterprises") }\end{array}$ & $\begin{array}{l}\text { Fully private or } \\
\text { restricted to } \\
\text { limited set of } \\
\text { authorised } \\
\text { nodes }\end{array}$ & $\begin{array}{l}\text { Network } \\
\text { operator only }\end{array}$ & $\begin{array}{l}\text { Network } \\
\text { operator only }\end{array}$ & $\begin{array}{l}\text { External bank } \\
\text { ledger shared } \\
\text { between parent } \\
\text { company and } \\
\text { subsidiaries }\end{array}$ \\
\hline
\end{tabular}

Source: (OECD, n.d.[45]).

\section{Enhancing traceability and authentication of pesticide products along the supply chain}

\section{What are the policy responses?}

As discussed in Section 2, the authentication and traceability of pesticides have been severely challenged by illegal practices - e.g. the use of forged labels and transport documents - in view of the increasing complexity of supply chains.

At present, the authentication and traceability of pesticides relies mainly on the labelling of both products and the containers, as well as on shipping documents - e.g. bills of lading and export documents - that should include information on product content, lot or batch number, origin and destination, and means and routes of transportation. ${ }^{13}$ However, transport documents are still largely paper-based and transmitted from one party to another along the supply chain, creating significant opportunities for fraud, errors and inefficiencies (Jouanjean, 2019[42]). Labels are not always explicit and can be easily tampered with. Moreover, countries have different standards regarding the content and format of labels, which makes it challenging for border and regulatory authorities to determine whether or not a label is authentic (Gaspar, $\left.2019_{[44]}\right) .{ }^{14}$

A more robust system is required to trace ready-to-use pesticides and upstream agricultural chemicals. End-to-end supply chain transparency would enable closer monitoring of the supply chain, help detect points of failure, and reduce response time in case of incident (Singh et al., 2017[47]; Mace and Luda di Cortemiglia, 2016[2]). Moreover, by capturing all stakeholders involved in the supply chain and their respective roles and responsibilities, full traceability can create accountability (Singh et al., 2017[47]).

\footnotetext{
${ }^{13}$ In principle, the batch number should be available on all pesticide products, enabling traceability back to their original batch and identification of their origin.

14 The United Nations Globally Harmonized System of Classification and Labelling of Chemicals (GHS) provides guidelines for hazard communication and labelling standards for chemical products, including pesticides. This can be used as a baseline for the international harmonisation of pesticide labelling (United Nation, 2011 [74]).
} 
Finally, improved pesticide traceability would reinforce consumer trust in products, as they would be able to more easily verify their provenance and authenticity prior to use.

\section{How can new digital technologies help?}

The core characteristics of blockchain enable secure peer-to-peer transactions - i.e. exchange of value and data - between parties with no prior transacting relationship. Until now, blockchain technology has been mainly used in the financial sector for monetary transactions, with Bitcoin being the most famous of these applications. However, blockchain can also benefit other sectors and other, non-monetary, purposes. In particular, blockchain has been considered an efficient tool for supply chain management, with potential applications for supply chain due diligence and tracking from origin to distribution for food products, medicines, and natural resources (Berryhill, Bourgery and Hanson, 2018[43]; OECD, 2019[48]]).

Blockchain enables asset tracking and authentication because of its ability to create unique identities for individual items (Radocchia, 2018[49]). A physical asset can be tracked in the blockchain by associating it to a unique digital asset. This process is called "tokenisation" (Box 3). The token (digital asset) can be, for instance, a digital representation of a good, a container or a shipment. Each change of state of this token (e.g. a change of ownership or arrival at a port of entry) is registered and time stamped on the blockchain (Gaspar, 2019[44]). The representation of a supply chain through a blockchain thus provides a digital database that permanently records, tracks, monitors, and transacts physical and digital assets (Tripoli and Schmidhuber, 2018[50]).

In the case of product tracking, an immutable link must be established between the product and its digital life on the blockchain for the transactions to be fully tamper-proof. This can be ensured through the use of innovative packaging technologies such as quick response (QR) codes, the more advanced radio frequency identification (RFID) chips, or crypto-anchors (Tripoli and Schmidhuber, 2018[50]). ${ }^{15}$ Once this immutable product-process link has been established, transactional data are recorded and verified by the blockchain - in a transparent and immutable fashion - as the product moves from the manufacturer to final consumer. Each transaction that is processed on the blockchain can carry transaction details and specific attributes of the product that can be added by supply chain actors (Tripoli and Schmidhuber, 2018[50]). Everyone with access to the blockchain can therefore examine the product's movements at every step of the supply chain and access real time information about the product being shipped (Jouanjean, 2019[42]).

Figure 6 gives an example of the type of digital information that could be entered into the blockchain by the stakeholders at each stage of the pesticide supply chain. In order to have full product traceability, the manufacturer would first register each of their products on the blockchain and upload information on the name, chemical composition, batch number, and type of packaging used. The blockchain will then be updated each time the product changes hands. Other types of information that would be recorded include the name and address of each participant, the dates of shipment and import, and the quantities of pesticide that are shipped and imported.

\footnotetext{
${ }^{15}$ Crypto-anchors are tamper-proof digital fingerprints that are embedded in products, or parts of products, and linked to the blockchain to prove product authenticity.
} 
Figure 6. Information on the pesticide supply chain entered into the blockchain

\begin{tabular}{l|l|}
\hline \multicolumn{1}{l|}{ MANUFACTURER } & \multicolumn{1}{|c|}{ FORMULATER } \\
- Pesticide name & - Name of base \\
and composition & material used \\
- Date of & - Name and address \\
of provider \\
- Batch number & - Product \\
- Type of packaging & composition/recipe \\
- Name and address & - Destination country \\
of manufacturer and & \\
purchaser & \\
- Date of sale & \\
- Destination country & \\
\hline
\end{tabular}

\begin{tabular}{|l|}
\hline \multicolumn{1}{|c|}{ EXPORTER } \\
- Pesticide name \\
- Name and address \\
of exporter \\
- Name, address \\
and country of \\
consignee \\
- Date of shipment \\
- Quantity shipped \\
- Registration \\
dossier \\
- Export certificate \\
\hline
\end{tabular}

\begin{tabular}{|l|}
\hline \multicolumn{1}{|c|}{ TRANSPORTER } \\
- Invoices \\
- Material data \\
safety sheets \\
- Export certificates \\
- Electronic export \\
information \\
- Packaging lists \\
\end{tabular}

\begin{tabular}{|l|}
\hline \multicolumn{1}{|c|}{ IMPORTER } \\
- Pesticide name \\
- Name and address \\
of importer \\
- Date of import \\
- Name, address \\
and country of \\
consignor \\
- Date of shipment \\
by consignor \\
- Quantity imported \\
\hline
\end{tabular}

\begin{tabular}{|l|}
\hline \multicolumn{1}{|c|}{ RETAILER } \\
- Pesticide name \\
- Name and address \\
of supplier and \\
purchaser \\
- Date of purchase \\
and sale \\
- Batch numbers \\
- Pack size \\
- Quantity/volume \\
purchased and sold \\
\end{tabular}

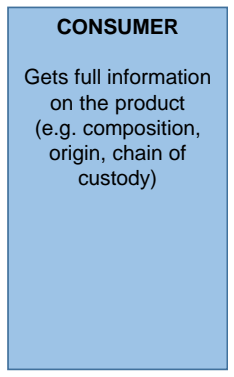

Note: Example of, but non-exhaustive, set of information.

Source: Authors based on OECD BPG to Identify Illegal Trade of Pesticides (OECD, 2019[28]).

Consequently, blockchain-based systems can allow for the rapid identification and reporting of suspicious activities within the supply chain and for the legal accountability of fraudulent behaviour (Radocchia, 2018[49]; Tripoli and Schmidhuber, 2018[50]). For instance, if a product or a container is diverted (e.g. sold to an unauthorised dealer), the disappearance of these items from the supply chain can be quickly detected - due to the observable inconsistencies between quantities shipped and imported - and traced back to the last party that had custody. Counterfeit and fake goods will also be easier to identify because they will not be assigned a registered blockchain identity (Radocchia, 2018[49]). The monitoring of the pesticide supply chain using blockchain would therefore make it much more difficult for illegal actors to sell their products, reducing the attractiveness and the "risk-profit" margin associated with this criminal activity (Radocchia, 2018[51]). Moreover, consumers would be able to easily verify the product's authenticity and access key information on the product they buy - e.g. by scanning a QR code on product packaging - thereby enabling more informed purchasing decisions (World Economic Forum, 2018[52]).

Several blockchain pilot applications have been tested and are being implemented in the agro-food sector. For instance, IBM has developed a blockchain tracking system to promote safer and smarter food supply chains. IBM Food Trust connects participants across the food supply chain (i.e. producers, suppliers, manufacturers, retailers, and consumers) through a permanent and shared record of transaction and food system data, significantly reducing opportunities for fraud. Walmart and Carrefour have adopted this technology to provide consumers with greater trust in their products and to differentiate their brands from their competitors (IBM, n.d.[53]). A growing number of start-ups are also developing blockchain-based solutions to trace food products from source to store (e.g. Ambrosus), provide agricultural supply chain actors with better data on crop production (e.g. Ripe), or to curb illegal fishing and fake certifications (e.g. Provenance) (Tripoli and Schmidhuber, 2018[50]).

Other blockchain applications currently in development focus on improving the traceability of agricultural inputs. For instance, the SICPA blockchain-based system aims to enhance the traceability of seeds in Brazil and ensure regulatory compliance. ${ }^{16}$ SICPA is also working with the United Nations Interregional Crime and Justice Research Institute (UNICRI) to develop blockchain-based systems to address supply chain security risks related to illegal pesticides (UNICRI, n.d.[54]). Finally, the OECD Seed Scheme is currently exploring how blockchain technology can improve the security of the existing paper-based seed lot identification and traceability system in place in OECD countries (Gaspar, 2019[44]).

\footnotetext{
${ }^{16}$ SICPA is a global provider of secured authentication, identification, and traceability solutions.
} 


\section{Challenges to the implementation of new digital technologies}

As with many emerging technologies, there are several risks to manage and challenges to overcome in order to harness the full potential of blockchain (World Economic Forum, 2018[52]).

First, building and deploying blockchain solutions requires significant technical and financial resources compared to traditional solutions such as centralised databases (Leon, 2018[55]). This includes the high investment costs required for information technology (IT) development and infrastructure, which have been estimated at USD 660000 for private blockchain solutions (EY, 2019[56]). In the case of a blockchain application for supply chain traceability, significant investment costs are also required to link physical products to their digital life on the blockchain (OECD, n.d.[45]). Legitimate manufacturers would have to invest in new packaging technologies to make sure this link cannot be replicated (Tripoli and Schmidhuber, 2018[50]). These large upfront costs are hampering widespread deployment of blockchain technology (Berryhill, Bourgery and Hanson, 2018[43]). The adoption of blockchain in developing countries - where illegal pesticides is a major issue - seems particularly challenging given the more limited financial resources and often lower quality of the IT infrastructure.

The lack of quality control of the information initially entered into the blockchain is another challenge for supply chain applications. While blockchain provides data immutability, there is no mechanism to guarantee the truthfulness of the information uploaded at the origin, which can significantly reduce the value of blockchain to supply chain actors and end-users. To eliminate opportunities for fraud, adequate regulations to control data processes and the establishment of data standards are required (Jouanjean, 2019[42]; Berryhill, Bourgery and Hanson, 2018[43]). The combination of blockchain with other technologies such as the Internet of Things (loT) (e.g. sensors) can also help reduce concerns over data quality by minimising human input into the shared ledger (OECD, 2019[48]).

Finally, the current absence of an adequate legal and regulatory framework for blockchain applications hinders the widespread deployment of this technology. For supply chain applications, a particular concern relates to the regulatory implications regarding data security and privacy amongst participants (World Economic Forum, 2018[52]). Transactions may include some types of confidential information, such as personal data or data related to business processes, that participants do not wish to become public knowledge or that data privacy regulations may prevent from being accessible. Careful consideration should be given to the type of data that should be protected, while still providing incentives to supply chain actors to share key data that are essential to guaranteeing transparency (Tripoli and Schmidhuber, 2018[50]).

\section{Improving monitoring and control of trade in pesticides}

\section{What are the policy responses?}

The globalisation and growth of pesticide trade has complicated the implementation and reduced the effectiveness of traditional trade control policies. As a result, a large share of illegal pesticides has been moving through legitimate supply chains without detection or seizure (Section 2). The effectiveness of trade control policies for pesticide products is also constrained by lack of awareness (or interest) of responsible authorities, poor inter-agency co-operation at national and international levels, and the limited financial resources for qualified staff, equipment and laboratory testing at customs borders (Food Chain Evaluation Consortium, 2015[12]; Mace and Luda di Cortemiglia, 2016[2]).

Customs agencies play a crucial role in detecting and inspecting suspicious shipments of pesticides. In particular, customs risk analysis carried out at the border should be at the forefront of any anti-smuggling 
strategy. ${ }^{17}$ The wider adoption of customs analysis and risk management systems - as opposed to random checks - would enable higher detection rates of illegal shipments. Pesticide imports are mainly controlled through the inspection of supporting documentation, visual control of packaging and labelling, and, in case of suspicion of illegality, sampling and laboratory analysis of the products (Malkov, Prischepa and Kutonova, 2015[22]).

Enhanced co-operation and information exchanges between the multiple agencies responsible for the control of pesticide trade (e.g. customs, regulatory authorities) would also enable a more effective detection of illegal pesticides. Greater efforts could be made by national agencies to set up tools and mechanisms to facilitate the exchange of operational and intelligence data, in particular with agencies in countries that are suspected to be a source of illegal pesticides (Ing. M.H. van Diesen, n.d.[9]; Malkov, Prischepa and Kutonova, 2015[22]). ${ }^{18}$ Amongst OECD countries, a Rapid Alert System has been implemented and is used by inspectors to exchange information on suspicious or rejected shipments of pesticides (OECD, 2019[28].$^{19}$

In particular, regulatory and customs authorities need to systematically exchange findings from control and investigation exercises in order to build risk profiles, which can then be uploaded in customs risk management systems. This should include information on commonly used methods to smuggle illegal pesticides (e.g. high risks entry points and pathways, seasonal variations), and on the type of actors involved and their modes of action (e.g. common product descriptions, common features of labelling and packaging) $\left(O E C D, 2018_{[10]}\right.$; Food Chain Evaluation Consortium, $\left.2015_{[12]}\right) .{ }^{20}$ Some national agencies around the world are using internal communication channels and automated risk management systems to fight trade in illegal pesticides (Box 6).

\section{Box 5. Border agency co-operation: Insights from the OECD Trade Facilitation Indicators (TFIs)}

Redundant or sequential controls, duplicative documentation requirements, and insufficient coordination amongst different agencies at the border can cause delays, complicate compliance by traders, and strain border post resources. Border agency co-ordination should thus aim to increase operational efficiency, reduce compliance costs for traders and enforcement costs for authorities, and facilitate legitimate trade.

Border agency co-operation shifts the focus beyond the traditional customs-specific trade facilitation agenda to a new and more comprehensive "whole-of-government" approach to reform. This new approach relies less on institution-specific reform and more on a wider trade supply chain approach designed to tackle the major issues that traders face in navigating regulatory requirements.

\footnotetext{
${ }^{17}$ Risk analysis is used by customs agencies to identify and quantify the risk associated with a specific shipment and determine the level of control required.

${ }^{18}$ As illustrated by the OECD Trade Facilitation Indicators (TFIs), the implementation of inter-agency and cross-border co-operation remains a challenge (Box 5).

${ }^{19}$ As of October 2017, 115 notifications of suspicious shipments had been reported, enabling the seizure of one illegal shipment of pesticides (presentation JWPTE Oct 2017).

20 Other types of information that should be recorded and periodically updated by regulatory authorities include: any pesticides or active ingredients which are particularly common targets of illegal operators; the use of any specific HS or $\mathrm{CN}$ codes; key words used on customs declarations and other documentation; common inconsistencies between documents and declarations (OECD, 2018[10]).
} 
Yet significant implementation challenges remain, as highlighted by the OECD Trade Facilitation Indicators (TFIs). The TFIs were developed in 2012 to support governments in their efforts to improve border procedures, reduce trade costs, and reap greater benefits from international trade. They currently cover the full spectrum of administrative procedures at the border for more than 160 countries across income levels, geographical regions, and development stages.

The OECD TFls highlight that there is considerable scope for further improvements in the area of border agency co-operation - both domestic and cross-border - despite the steps taken by a significant number of surveyed economies to promote the exchange of information and mutual assistance across agencies involved in the management of trade.

At the domestic level, practices such as sharing inspection results and co-ordinating risk management mechanisms continue to gain ground in countries at all levels of development. However, the development of interconnected computer systems and real time availability of pertinent data that can help agencies streamline their processes and improve their interactions remain incomplete across all regions.

Co-operation with border agencies in neighbouring and third countries is even more challenging than domestic border agency co-operation. Good progress has been made worldwide on the alignment of procedures and formalities which are being implemented in most surveyed countries. Efforts to deepen cross-border agency co-operation through automation are also underway, but much more can be done. Advances have been made mainly in OECD countries and mostly in the area of the harmonisation of data requirements and documentary controls. In other areas, such as co-ordination of computer systems, risk management co-operation, and the systematic sharing of control results amongst neighbouring countries, implementation by OECD countries and other high-income economies is again significantly more advanced than in other countries surveyed.

Source: $(\mathrm{OECD}, 2018[57])$.

Co-operation should also be encouraged between national authorities and the private sector. Closer links between custom officers and intellectual property rights (IPRs) holders, for instance, would improve detection processes as brand owners are experts at identifying counterfeits and are best positioned to monitor their value chain (Metivier and Simonelli, 2017[58]).

Finally, new trends in trade, such as online trade, have also challenged traditional trade control policies as these complicate the detection of illegal products at the border and retail level. Online trade is profoundly changing the function of control authorities and forcing them to rethink their strategies. The latter will have to shift their focus to increased monitoring of the growing sale of plant protection products over the Internet.

\section{Box 6. The "one check principle", a successful example of inter-agency co-operation}

In the Netherlands, the Dutch Food and Consumer Product Safety Authority (NVWA) is responsible for enforcing regulations related to pesticides. The NVWA works closely with customs, the police, and the Public Prosecution Service (OM) to prevent non-authorised and counterfeit pesticides from reaching the market. Activities that seek to control pesticide activities mainly target the Port of Rotterdam and Schiphol Airport. These four agencies use customs communication channels to exchange operational information. 
The NVWA is in charge of defining and updating risk profiles, and entering indicators into the customs automated risk management system (ARMS), which can automatically assess the risks associated with a specific shipment and recommend the appropriate level of control and inspection procedure. Indicators of risks encompass the presence of an active ingredient, the use of a description for the goods or the names of importing companies that are known to use illegal pesticides.

Shipments that are selected by the ARMS are inspected by both custom officers and the NVWA. Customs are responsible for co-ordinating these combined inspections and ensuring that only one physical check is carried out, thus minimising the loss of time in the logistics chain. The NVWA then communicates the outcome of its inspection to customs in order to ensure that a shipment is not released.

Besides reducing time and costs for traders, the "one check principle" enables the different agencies responsible for the control of illegal pesticides to benefit from each other's knowledge and expertise. The NVWA also offers training to customs officials when required

Source: (Ing. M.H. van Diesen, n.d. $(99)$.

\section{How can new digital technologies help?}

Blockchain technology can improve the monitoring and control of pesticide trade by facilitating data exchange and co-operation among participants in the pesticide supply chain and providing easy access to a range of information about the products being traded. Beyond blockchain, other digital technologies, such as big data analytics and artificial intelligence (Al), offer opportunities for better risk management at the border, automated inspections of containers and cargos, and the monitoring of online trade.

\section{Blockchain}

Compared to traditional paper-based systems or centralised databases, blockchain solutions can significantly reduce the time and costs associated with information exchanges between multiple stakeholders, as well as the risks of fraud, errors, and inefficiencies (Berryhill, Bourgery and Hanson, 2018[43]). Blockchain can bring together and connect manufacturers, transporters, customs and other government agencies, and retailers into a single platform (SigmaLedger, 2018[59]). A shared and immutable ledger in which all supply chain participants log their activities creates a single source of trust and therefore facilitates data exchange and co-operation. The most appropriate type of blockchain ledger for the pesticide supply chain is perhaps a public permissioned blockchain, where only supply chain participants can record new transactions but these transactions can be made transparent to all (e.g. consumer) (Box 4).

The integration of blockchain into the pesticide supply chain would also offer the opportunity for authorities from different countries to agree on what type of data should be entered into the system at each step of the pesticide supply chain, and to potentially integrate other types of relevant digital information (e.g. pesticide registration dossier) (Figure 6). Quick access to key information on the products being shipped would support regulatory and control authorities in identifying suspicious activities.

Finally, blockchain enables cross-organisation automation through the execution of smart contracts $($ OECD, 2019 $[48])$. By automating contractual processes - e.g. the terms for payment and delivery of goods - and automatically dispersing customs duties upon acceptance of goods at the border, smart contracts can further reduce the risk of fraudulent behaviour in the supply chain, and result in cost reductions and efficiency gains for all parties involved (OECD, 2019[48]; Law, 2017[60]; Tripoli and Schmidhuber, 2018[50]). 


\section{Big data analytics}

Some national customs agencies are already using big data as part of their risks analysis and fraud identification efforts (Jouanjean, 2019 ${ }_{[42]}$; Okazaki, 2017[46]). Big data enables customs structured data accumulated over time (e.g. data on investigation findings and risk profiles) to be enriched with new types of data from a wide variety of sources (e.g. intelligence on other criminal activities, data from sensors and collected by the Internet of things), thereby offering more accurate and complete information on the nature and the level of risks customs agencies are facing. In particular, by combining and correlating different categories of data - such as international trade data, government and industry data - big data techniques can estimate the risk that an actor is engaged in some form of illegal practice or quickly flag with greater accuracy a high-risk cargo (Trase, 2016[61]) (Okazaki, 2017[46]). These decision-making and predictive intelligence tools can thus assist customs staff by recommending priority pesticide shipments for inspection and the type of control procedures they should carry out, allowing greater prioritisation in the allocation of limited custom resources. Ultimately, the integration of big data into customs risk management systems can enable border authorities to continue fulfilling their monitoring mission despite increasing trade flows (Jouanjean, 2019[42]).

Big data analytics are used as a tool for fighting environmental crimes, including illegal timber, fisheries and wildlife trade (Trase, 2016[61]; Dick et al., 2015[62] $)$ (Dick et al., 2015[62]). The Environmental Investigation Agency (EIA) - a non-profit NGO - has been pioneering the integration of big data solutions to form the basis of predictive analytics. Since 2006, the EIA has been using the IBM big data system to tackle illegal trade of endangered species and ivory. The system brings together in a single data base field reports from EIA's investigations and old case files, government, press and research reports, and information on enforcement actions taken worldwide. It also has the ability to integrate visual content, such as video and photographic documentation. This tool has helped the EIA to effectively investigate cases by providing comprehensive information on key criminal players and their prioritised targets (Davies, 2013[63]).

\section{Artificial intelligence $(A I)$}

Artificial intelligence has the potential to improve customs border management and fraud identification. Al robots can perform inspections on hazardous goods and repetitive tasks, such as monitoring containers and warehouses, thereby freeing customs staff to undertake other tasks. Al systems can be trained to detect risks more effectively in conjunction with other technologies, including sensors. Ultimately, automation could enable the monitoring of $100 \%$ of pesticide cargos, dramatically reducing the probability that illegal products cross borders and enter markets (Jouanjean, 2019 $\left.9_{[42]}\right)$.

Moreover, due to their ability to process verbal, visual and audio-visual content, Al methods such as machine learning and visual recognition algorithms can be used to monitor illegal trade on the Internet. Al systems could be trained to detect illegal pesticides offered on online platforms, based on specific characteristics of labels and packaging, or common names or product description that are known to be used for illegal pesticides. Mainstream online retail companies such as Amazon and Alibaba already use these techniques to identify and remove fake ads and counterfeit products from their platforms (Incisive Business Media Limited, 2019[64]). Until recently, analysing platforms or websites for evidence of illegal products required specially trained staff and a prohibitively large amount of time. An Al-supported approach can dramatically reduce the time needed to identify posts that contain evidence of illegal activity as they can quickly sift through thousands of images and textual data (Di Minin, 2018[65]). 


\section{Challenges to the implementation of new digital technologies}

The main challenge for supply chain co-operation through blockchain is the lack of interoperability between blockchain platforms, which prevents data sharing and access between separate networks. ${ }^{21}$ In order to create a blockchain system to track trade in pesticides, all public and private actors involved in the product supply chain would need to agree on common technical standards - e.g. how data should be shared and stored - and ensure the interoperability of their systems. Creating a standard data model for the pesticide supply chain is likely to involve numerous and lengthy discussions among participants (OECD, 2019[48]).

Supply chains actors would also need to reach agreement on sharing the costs for developing the necessary IT infrastructure and on the mode of governance of the platform - e.g. entry and exit of participants, validation of transactions, and roles and responsibilities of nodes. Getting all stakeholders aligned is likely to be challenging given the global nature and the large number of participants in pesticide supply chains (OECD, 2019 [48]).

Finally, the low usability of existing interfaces for blockchain ledgers - including poor user experience, low system speed, and lack of formalised blockchain protocols -hinders the widespread understanding and adoption of this technology (World Economic Forum, 2018[52]). The complexity and lack of education on blockchain technology means that the process of integrating all actors of pesticide supply chains into a blockchain is likely to be challenging and to take time (Tripoli and Schmidhuber, 2018[50]) (Berryhill, Bourgery and Hanson, 2018[43]).

The adoption of big data and Al by customs agencies also presents challenges. First, as with blockchain, the technical infrastructure and software costs of these technologies are high - estimated at about USD 180000 for a big data solution (Cooladata, 2019[66]). Moreover, customs agencies would have to hire knowledgeable experts to manage these complex tools, ${ }^{22}$ in addition to investing in the training of all customs staff to ensure they have the necessary skills and capacity to understand and accept these new technologies (Okazaki, 2017[46]; Bekker, 2019[67]). Such substantial investment costs represent a barrier to the adoption of these technologies, especially in developing countries with limited financial resources.

Other challenges linked to the adoption and use of big data and Al include the complexity of managing the quality of raw data as these technologies rely on a large amount of data collected from different sources. There are also concerns related to data privacy, confidentiality and cybersecurity, suggesting that these technologies cannot be put in place without a solid legal framework (Okazaki, 2017[46]).

\section{Policy responses beyond new digital technologies}

While new digital technologies hold significant promise for supporting policy actions on traceability and authentication, and the monitoring and control of trade, other policy responses are necessary to efficiently crack down on trade in illegal pesticides. Digital-based solutions alone are insufficient to address this issue.

Raising stakeholder awareness is key to fighting trade in illegal pesticides (Malkov, Prischepa and Kutonova, 2015[22] $)$. At present, actors at all stages of the pesticide supply chain are not sufficiently aware of the issue of trade in illegal pesticides to enable an effective crackdown on this criminal activity (Mace

\footnotetext{
21 There are currently hundreds of blockchain networks in operation or under development, each identifying and collecting information differently, and with different governance structures (OECD, n.d.[45]).

22 Human resources are considered to represent the highest costs for building big data solutions because the shortage of talent leads to high salaries in the big data industry (Harvey, 2017[71]).
} 
and Luda di Cortemiglia, 2016[2] $)$. Education and training on the risks associated with such products and how to identify them need to be provided to supply chain participants and end users through public-private collaboration. This would contribute to a higher rate of detection and seizure of illegal products throughout the supply chain and help to reduce farmer demand for cheap, un-authorised pesticides (Malkov, Prischepa and Kutonova, 2015[22]).

While new digital technologies may allow to identify criminal actors, strengthening sanctions for illegal pesticide offences and ensuring better law enforcement are also required. To date, trade in illegal pesticides has been associated with minor legal, including criminal, and financial consequences (Mace and Luda di Cortemiglia, 2016 $\left.{ }_{[2]}\right)$. Penalties vary markedly by country, but most have inadequate penalties that poorly reflect the threat these products pose to agriculture, the environment, human health, and the economy (Mace and Luda di Cortemiglia, 2016[2]; Moss, 2013[68]). Increasing the severity of the sanctions and the extent to which they are applied would act as a deterrence on illegal actors (Mace and Luda di Cortemiglia, 2016[2]).

Finally, there is a need to close loopholes found in different pieces of legislation that govern trade in pesticides. The lack of clarity and harmonisation has made it relatively easy for criminals to route their products to farmers. For instance, the legal framework governing in-transit consignments (i.e. consignments passing through non-destination countries) is often considered too weak or ambiguous to allow customs authorities to seize illegal shipments of pesticides (OECD, $\left.2011_{[1]}\right) .{ }^{23}$ Legally allowing customs to stop and test products in transit - based on false or incomplete documentation or the suspicion of the illegal nature of a shipment - could prevent illegal pesticides from entering the market. Simplified customs procedures for small packages have also resulted in the release of some illegal products onto the market (Europol/OHIM, 2015[39]). ${ }^{24}$

Legislation governing the waste management of seized counterfeit pesticides also needs to be reviewed. In most OECD countries, rules are such that the brand owner - i.e. the IPR holder - is responsible for the storage, disposal, or destruction of seized counterfeit pesticides. However, due to the high compliance costs of these liabilities, pesticide companies have requested that enforcement agencies stop seizing products that infringe on their trademark. Consideration should therefore be given to introducing legal provisions or mechanisms for the financing of such activities, including cost-sharing between brand owners and authorities (OECD, 2019[28]).

In order to prevent abuse of parallel imports via free trade zones (FTZs), it may be necessary to rethink the current legal framework on parallel imports and the repackaging of pesticide products (Food Chain Evaluation Consortium, $\left.2015_{[12]}\right) .{ }^{25}$ A possible solution would be to impose "double labelling" to facilitate the traceability of repackaged products, i.e. to require the inclusion of a copy of the original label on the repackaged pesticide or indication of the original batch number (OECD, 2018[10]). Another option could be to forbid the repackaging of pesticides for parallel imports (ECPA, 2008[25]).

Finally, online sales of pesticides are incompletely regulated and e-commerce websites often provide little information on the legal requirements for trading agricultural and food products (Jouanjean, 2019[42]). The

\footnotetext{
${ }^{23}$ There is often a lack of clarity on whether consignments that pass through third countries are considered to be in the market in those territories; this affects the ability of authorities to take action or on the range of actions that can be taken (OECD, 2018[10]).

${ }^{24}$ In the European Union, for instance, Regulation 608/2013 requires customs to notify the brand owner to check whether goods detained are genuine or counterfeit. If brand owners do not reply within a given period, the goods cannot be released in the European Union. However, rights holders often do not bother to take action if the amounts seized are low (Europol/OHIM, 2015[39]).

${ }^{25}$ See OECD Recommendation on countering illicit trade in FTZs (OECD, 2019[72]).
} 
British Pest Control Association and the Crop Protection Association have recently been working with eBay and other internet companies to stop online sales of unauthorised pesticides. eBay has since clarified its policies for the sale of pesticides and prohibits person-to-person sales. Only authorised eBay shops are allowed to sell pesticides on the platform (British Pest Control Association, n.d. [69]).

\section{Conclusion}

This paper has explored the potential of blockchain and other new digital technologies to support policy action to tackle trade in illegal pesticides, and has discussed the challenges associated with the adoption of these technologies.

The adoption of blockchain by participants in the pesticide supply chain would provide end-to-end product traceability, chain of custody, and access to real time information on the products being traded. This would allow for the rapid identification and reporting of problems within the supply chain, significantly reducing opportunities and incentives for fraud. Moreover, farmers would be able to easily verify a product's authenticity and provenance, enabling more informed purchasing decisions. It would also offer the opportunity for regulatory authorities from different countries to harmonize data requirements for trading pesticide products and to upload other types of relevant digital information into a shared system, facilitating the work of border and other control agencies.

Big data analytics and Al can also improve the effectiveness of trade control policies for pesticide products. Big data can improve risk management processes at the border, enabling quick and accurate identification of illegal pesticide shipments. Automation would also significantly reduce the risks of entry of illegal pesticides by making it possible to physically check $100 \%$ of the cargo. Moreover, Al methods such as machine learning and visual recognition algorithms could be used to monitor the increase in illegal pesticides on online platforms.

While holding great promise, the adoption of blockchain, big data, and AI hold a number of challenges. Among these, the substantial upfront costs - including the high costs for IT development and infrastructure - and their complexity hinder their widespread deployment. In developing countries - where financial resources for equipment and skilled staff may be more limited, and the quality of the IT infrastructure can be lower - these challenges are even more acute.

Finally, tackling trade in illegal pesticides will require the implementation of other policy actions beyond new digital technologies. These include raising awareness among supply chain actors on the risks that are associated with illegal pesticides and to provide training on how to identify them. Strengthening sanctions for illegal pesticide offences is necessary in order to provide greater deterrence to illegal actors. Lastly, it is necessary to review the legal framework that govern trade in pesticides so as to close loopholes that are currently being exploited by illegal actors to route their products to farmers.

Future research could focus on gathering more information on the current use of digital technologies for tackling illegal trade in pesticides, perhaps through industry surveys. This would allow a comparison of the benefits of using these technologies compared to traditional alternatives (e.g. older risk management and automation tools) in terms of detection rates (effectiveness) and cost and resource savings (efficiency). Once this baseline data and analysis are done, economic modelling research could focus on optimising the design of these systems to better support policy development and investment in modernising market monitoring systems. 


\section{References}

Aktar, M., D. Sengupta and A. Chowdhury (2009), "Impact of pesticides use in agriculture: their benefits and hazards", http://dx.doi.org/10.2478/v10102-009-0001-7.

Bekker, A. (2019), 7 Major Big Data Challenges and Ways to Solve Them, ScienceSoft, https://www.scnsoft.com/blog/big-data-challenges-and-their-solutions (accessed on 2 December 2019).

Berryhill, J., T. Bourgery and A. Hanson (2018), "Blockchains Unchained: Blockchain Technology and its Use in the Public Sector", OECD Working Papers on Public Governance, No. 28, OECD Publishing, Paris, https://dx.doi.org/10.1787/3c32c429-en.

British Pest Control Association (n.d.), eBay BPCA and Crop Protection Association leading the way on stewardship of online pesticides sales, https://bpca.org.uk/News-and-Blog/ebay-bpcaand-crop-protection-leading-the-way-on-stewardship-of-online-pesticide-sales (accessed on 11 September 2019).

Clarridge, C. and L. V.Mapes (2018), “Amazon, EPA reach \$1.2 million settlement over online sales of illegal pesticides", The Seattle Times, https://www.seattletimes.com/business/amazon/amazon-epa-reach-1-2-million-settlementover-online-sales-of-illegal-pesticides/.

Cooladata (2019), The True Cost of Building a Big Data Solution, https://www.cooladata.com/blog/true-cost (accessed on 3 December 2019).

Cunningham, M. (n.d.), Use of Pesticides: Benefits and Problems Associated with Pesticides, Study.com, https://study.com/academy/lesson/use-of-pesticides-benefits-and-problemsassociated-with-pesticides.html (accessed on 7 October 2019).

Davies, C. (2013), "Big Data and Analytics Helping to Protect Big Cats", National Geographic, https://blog.nationalgeographic.org/2013/02/12/big-data-and-analytics-helping-to-protect-bigcats/ (accessed on 4 October 2019).

Di Minin, E. (2018), “Using Al to monitor illegal wildlife trade”, Good news from Finland, http://www.goodnewsfinland.com/opinion/using-ai-to-monitor-illegal-wildlife-trade/.

Dick, V. et al. (2015), Harnessing Big Data to Combat Illegal Wildlife, Timber and Fisheries Trade, WILDLABS.NET, https://www.wildlabs.net/resources/thought-pieces/harnessing-bigdata-combat-illegal-wildlife-timber-and-fisheries-trade.

ECPA (2019), Maximum residue levels of pesticides, https://www.ecpa.eu/regulatory-policytopics/maximum-residue-levels-pesticides (accessed on 30 August 2019).

ECPA (2008), Counterfeit Pesticides Across Europe-2008.

European Crop Protection Association (2019), Counterfeit and Illegal Pesticides, https://www.ecpa.eu/stewardship/counterfeit-illegal-pesticides.

Europol (2020), "A record number of 1346 tonnes of illegal pesticides taken off the market in 2020 global operation Silver Axe", https://www.europol.europa.eu/newsroom/news/record- 
number-of-1-346-tonnes-of-illegal-pesticides-taken-market-in-2020-global-operation-silver-axe (accessed on 17 July 2020).

Europol (2019), Operation Silver Axe strikes for the fourth time seizing over 550 tonnes of illegal pesticides, https://www.europol.europa.eu/newsroom/news/operation-silver-axe-strikes-forfourth-time-seizing-over-550-tonnes-of-illegal-pesticides (accessed on 25 June 2019).

Europol (2018), Largest-ever seizure of illegal or counterfeit pesticides in Europol SILVER AXE operation, https://www.europol.europa.eu/newsroom/news/largest-ever-seizure-of-illegal-orcounterfeit-pesticides-in-europol-silver-axe-operation.

Europol (2017), 122 tons of illegal or counterfeit pesticides seized during operation Silver Axe II, https://www.europol.europa.eu/newsroom/news/122-tons-of-illegal-or-counterfeit-pesticidesseized-during-operation-silver-axe-ii (accessed on 2 September 2019).

Europol (2015), Huge seizures of 190 tonnes of counterfeit pesticides, https://www.europol.europa.eu/newsroom/news/huge-seizures-of-190-tonnes-of-counterfeitpesticides (accessed on 2 September 2019).

Europol (2011), Growth in the trade in counterfeit and other illegal pesticides across Europe.

Europol/OHIM (2015), 2015 Situation Report on Counterfeit in the European Union, https://euipo.europa.eu/ohimportal/documents/11370/80606/2015+Situation+Report+on+Cou nterfeiting+in+the+EU (accessed on 7 May 2019).

Europol/OHIM (2012), Awareness Conference on Fake and Illicit Pesticides - Report and Conclusions.

EY (2019), Total cost of ownership for blockchain solutions.

FAO/WHO (2013), International Code of Conduct on the Distribution and Use of Pesticides Guidelines on data requirements for the registration of pesticides.

FAOSTAT (2019), Pesticides Trade, http://www.fao.org/faostat/en/\#data/RT (accessed on 3 September 2019).

Federation of Indian Chambers of Commerce and Industry (2015), Study On Sub - Standard, Spurious/Counterfeit Pesticides in India, http://dx.doi.org/10.1016/s0166-4972(01)00041-4.

Fishel, F. (2015), "The Global Increase in Counterfeit Pesticides", http://edis.ifas.ufl.edu.

Food Chain Evaluation Consortium (2015), Ad-hoc study on the trade of illegal and counterfeit pesticides in the EU - Executive summary, European Comission.

Gaspar, C. (2019), "How digital technologies could improve the management and implementation of the OECD Seed Schemes", OECD.

Guyer, R. and C. Davreux (2012), The problem of Counterfeit and Illegal Pesticides in Africa Middle East.

Harvey, C. (2017), “Top Big Data Challenges", Datamation, https://www.datamation.com/bigdata/big-data-challenges.html (accessed on 3 December 2019).

IBM (n.d.), IBM Food Trust, https://www.ibm.com/blockchain/solutions/food-trust (accessed on 
26 September 2019).

Incisive Business Media Limited (2019), Amazon introduces Al-based initiative to help identify counterfeit listings, https://www.computing.co.uk/ctg/news/3071959/amazon-introduces-aibased-initiative-to-help-identify-counterfeit-listings (accessed on 4 October 2019).

Ing. M.H. van Diesen (n.d.), "Highlights on the trade in non-authorized and counterfeit pesticides", World Customs Organization, https://mag.wcoomd.org/magazine/wco-news80/highlights-on-the-trade-in-non-authorized-and-counterfeit-pesticides/.

Jouanjean, M. (2019), "Digital Opportunities for Trade in the Agriculture and Food Sectors", OECD Food, Agriculture and Fisheries Papers, No. 122, OECD Publishing, Paris, https://dx.doi.org/10.1787/91c40e07-en.

Kaur, H. and H. Garg (2014), "Pesticides: Environmental Impacts and Management Strategies", in Pesticides - Toxic Aspects, InTech, http://dx.doi.org/10.5772/57399.

Law, A. (2017), Smart Contracts and their Application in Supply Chain Management, Massachusetts Institute of Technology.

Leon, K. (2018), "3 Barriers to the adoption of blockchain technology", Medium, https://medium.com/pikciochain/3-barriers-to-the-adoption-of-blockchain-technologyb47b924a186a (accessed on 2 October 2019).

Mace, R. and V. Luda di Cortemiglia (2016), Illicit Pesticides, Organized Crime and Supply Chain Integrity, United Nations Interregional Crime and Justice Research Institute (UNICRI).

Mahmood, I. et al. (2016), "Effects of pesticides on environment", in Plant, Soil and Microbes: Volume 1: Implications in Crop Science, Springer International Publishing, http://dx.doi.org/10.1007/978-3-319-27455-3 13.

Malkov, M., S. Prischepa and T. Kutonova (2015), Counteraction to Counterfeit and Contraband Pesticides - Methodology, OSCE, ENVSEC, https://www.osce.org/secretariat/192516?download=true.

Metivier, J. and F. Simonelli (2017), Digital Traceability in the Fight against Illicit Trade: Improving rules and practices, https://www.ceps.eu/wpcontent/uploads/2017/11/Event\%20report \%201llicit\%20Trade \%20CEPSMSL\%20November\%202017.pdf (accessed on 17 September 2019).

Moss, M. (2013), Keep it real.

National Pesticide Information Center (2016), Pesticides and the Environment, http://npic.orst.edu/envir/.

National Pesticide Information Center (n.d.), Pesticide Half-life, http://npic.orst.edu/factsheets/half-life.html (accessed on 9 October 2019).

OECD (2019), Is there a role for blockchain in responsible supply chains?, http://www.oecd.org/finance/oecd-blockchain-policy-forum.htm.

OECD (2019), Recommendation of the Council on Countering Illicit Trade: Enhancing Transparency in Free Trade Zones, OECD Legal Instruments, 
https://legalinstruments.oecd.org/en/instruments/OECD-LEGAL-0454 (accessed on 10 December 2019).

OECD (2019), Recommendation of the Council on Countering the Illegal Trade of Pesticides, https://legalinstruments.oecd.org/public/doc/642/642.en.pdf (accessed on 28 August 2019).

OECD (2018), Best Practice Guidance to Identify Illegal Trade of Pesticides, OECD Environment Health and Safety Publications Series on Pesticides No. 99.

OECD (2018), Trade facilitation and the global economy, OECD Publishing, https://doi.org/10.1787/9789264277571-en.

OECD (2014), Report on an OECD Survey on the Assessement of the risks from obsolete Pesticides in OECD countries, http://www.oecd.org/officialdocuments/publicdisplaydocumentpdf/?cote=ENV/JM/MONO(2014 26\&doclanguage =en (accessed on 28 August 2019).

OECD (2011), Report of the OECD Seminar on Risk Reduction through Prevention, Detection and Control of the Illegal International Trade in Agricultural Pesticides.

OECD (2001), OECD Glossary of Statistical Terms - Pesticide Definition, https://stats.oecd.org/glossary/detail.asp?ID=2052 (accessed on 8 October 2019).

OECD (n.d.), OECD Blockchain Primer.

OECD/FAO (2019), OECD-FAO Agricultural Outlook 2019-2028, OECD Publishing, Paris/Food and Agriculture Organization of the United Nations, Rome, https://dx.doi.org/10.1787/agr outlook-2019-en.

Okazaki, Y. (2017), "Implications of Big Data for Customs - How It Can Support Risk Management Capabilities", World Custom Organization, http://www.wcoomd.org/ /media/wco/public/global/pdf/topics/research/research-paperseries/39 okazaki big-data.pdf (accessed on 4 October 2019).

Pariona, A. (2017), The Environmental Impact of Pesticides, WorldAtlas.com, https://www.worldatlas.com/articles/what-is-the-environmental-impact-of-pesticides.html (accessed on 13 May 2019).

Pesticide Action Network (2010), "Environmental effects of pesticides. An impression of recent scientific literature".

Pesticide Action Network UK (2017), Impacts of pesticides on the environment, http://www.panuk.org/our-environment/ (accessed on 13 May 2019).

Popp, J., K. Petö and J. Nagy (2015), "Pesticide productivity and food security. A review", Agronomy for Sustainable Development, https://hal.archives-ouvertes.fr/hal01201350/document (accessed on 8 October 2019).

Radocchia, S. (2018), "Combating Illicit Markets With Blockchain: Smart Supply Chains Solutions", Forbes, https://www.forbes.com/sites/samantharadocchia/2018/07/03/combatingillicit-markets-with-blockchain-smart-supply-chains-solutions/\#1e97d691e1d5.

Radocchia, S. (2018), “Why Blockchain Can Be An Effective Tool For Fighting Environmental 
Crime", Forbes, https://www.forbes.com/sites/samantharadocchia/2018/05/10/whyblockchain-can-be-an-effective-tool-for-fighting-environmental-crime/\#1284170d589f.

RSK ADAS Ltd (2015), "Counterfeit and illegal pesticides in food supply chains- what should businesses be doing to minimise the risk?", https://www.adas.uk/News/counterfeit-and-illegalpesticides-in-food-supply-chains-what-should-businesses-be-doing-to-minimise-the-risk.

SigmaLedger (2018), How Blockchain can help Governments to fight counterfeiting, https://blog.sigmaledger.com/how-blockchain-can-help-governments-to-fight-counterfeiting7379294bfa69.

Singh, D. et al. (2017), "Food Traceability and Safety: From Farm to Fork - A Case Study of Pesticide Traceability in Grapes", Journal of Advanced Agricultural Technologies, Vol. 4/1, pp. 40-47, http://dx.doi.org/10.18178/joaat.4.1.40-47.

Streloke, M. (2018), "Illegal trade of plant protection products: a highly profitable way to smuggle chemicals", Journal of Consumer Protection and Food Safety, Vol. 13/3, pp. 255-256, http://dx.doi.org/10.1007/s00003-018-1177-6.

Trase (2016), Using big data to track illegality in the global timber trade, https://medium.com/trase/using-big-data-to-track-illegality-in-the-global-timber-trade$\underline{664 a 3 c 65251 \mathrm{e}}$.

Tripoli, M. and J. Schmidhuber (2018), Emerging Opportunities for the Application of Blockchain in the Agri-food Industry Agriculture, FAO/ICTSD.

UN environment (2018), Fake pesticides, real problems: addressing Ukraine's illegal and counterfeit pesticides problem, https://www.unenvironment.org/news-and-stories/story/fakepesticides-real-problems-addressing-ukraines-illegal-and-counterfeit.

UNICRI (n.d.), Security Improvements, through Research, Technology and Innovation (SIRIO), http://www.unicri.it/special topics/SIRIO Security and Innovation/ (accessed on 26 September 2019).

United Nation (2011), Globally Harmonized System of Classification and Labelling of Chemicals (GHS), https://www.unece.org/fileadmin/DAM/trans/danger/publi/ghs/ghs rev04/English/STSG-AC10-30-Rev4e.pdf (accessed on 18 September 2019).

US EPA (n.d.), About Pesticide Registration, 2019, https://www.epa.gov/pesticideregistration/about-pesticide-registration (accessed on 28 August 2019).

Wajsman, N., C. Arias Burgos and C. Davies (2017), The Economic Cost of IPR Infringement in the Pesticides Sector, European Union Intellectual Property Office (EUIPO), http://www.euipo.europa.eu.

World Economic Forum (2018), Building Block(chain)s for a Better Planet.

WTO and FAO (2013), International Code of Conduct on the Distribution and Use of Pesticides Guidelines on data requirements for the registration of pesticides, http://www.fao.org/3/abc870e.pdf (accessed on 6 June 2019). 